\title{
The emission spectrum of the strong Fe II emitter BAL Seyfert 1 galaxy IRAS $07598+6508^{\star}$
}

\author{
M.-P. Véron-Cetty ${ }^{1}$, M. Joly ${ }^{2}$, P. Véron ${ }^{1}$, T. Boroson ${ }^{3}$, S. Lipari ${ }^{4}$, and P. Ogle \\ 1 Observatoire de Haute Provence, CNRS, 04870 Saint-Michel l'Observatoire, France \\ e-mail: [mira.veron;philippe.veron]@oamp.fr \\ 2 Observatoire de Paris-Meudon, 5 place J. Janssen, 92195 Meudon, France \\ e-mail: Monique.Joly@obspm.fr \\ 3 National Optical Astronomy Observatory, 950 North Cherry Avenue, Tucson, AZ 85719, USA \\ e-mail: tyb@noao.edu \\ ${ }^{4}$ Cordoba observatory and CONICET, Laprida 854, 5000 Cordoba, Argentina \\ e-mail: lipari@mail.oac.uncor.edu \\ 5 Spitzer Science Center, California Institute of Technology, MS 220-6, Pasadena, CA 91125, USA \\ e-mail: ogle@ipac.caltech.edu
}

Received 22 September 2005 / Accepted 3 February 2006

\section{ABSTRACT}

\begin{abstract}
The narrow-line Seyfert 1 galaxy IRAS $07598+6508$ is known to be a stong Fe II emitter. The analysis of several high $S / N$ ratio spectra shows that its spectrum is dominated by a relatively narrow "broad line" region $\left(1780 \mathrm{~km} \mathrm{~s}^{-1} F W H M\right)$ emitting not only Fe II, but also Ti II and Cr II lines. Although we were unable to find a completely satisfactory physical model, we got the best agreement with the observations with collisional rather than radiative models, with a high density $\left(n=10^{15} \mathrm{~cm}^{-3}\right)$, a high column density $\left(N_{\mathrm{H}}=\right.$ $10^{25} \mathrm{~cm}^{-2}$ ) and a microturbulence of $100 \mathrm{~km} \mathrm{~s}^{-1}$. This BLR is qualitatively similar to the one observed in IZw 1 . We have not found traces in IRAS $07598+6508$ of the narrow line regions found in I Zw 1.
\end{abstract}

Key words. galaxies: Seyfert - galaxies: individual: IRAS 07598+6508

\section{Introduction}

IRAS 07598+6508 was identified as a 14.3 mag starlike AGN candidate by de Grijp et al. (1987). Optical and infrared images are dominated by the point-source nucleus (Scoville et al. 2000; Surace \& Sanders 2000; Kim et al. 2002). An HST image, published by Boyce et al. (1996) and Canalizo \& Stockton (2000), shows a great number of knots, presumably OB associations.

This object was shown to be a Seyfert 1 galaxy by Sanders et al. (1988). Its redshift, $z=0.149$, corresponds to a distance of $630 \mathrm{Mpc}^{1}$. It is a very strong Fe II emitter (Lawrence et al. 1988; Low et al. 1988; 1989) and a BAL QSO (Boroson \& Meyers 1992). It is an ultraluminous IR galaxy with a bolometric luminosity greater than $10^{12} L_{\odot}$ (Sanders et al. 1988). It is a weak hard X-ray source (Gallagher et al. 1999; Green et al. 2001; Imanishi \& Terashima 2004). It contains a weak compact $(<0$ ' 1$)$ nuclear radio source $\left(S_{15 \mathrm{GHz}}=2.9 \mathrm{mJy}\right)$ (Nagar et al. 2003).

The aims of this paper are to identify all emission lines in its spectrum and to try to determine the physical conditions in the emission line regions. Similarities and differences with I Zw 1, another well studied object, will also be noted.

\footnotetext{
* Appendix A is only available in electronic form at http://www. edpsciences.org

1 Throughout this paper, we use $H_{\mathrm{o}}=70 \mathrm{~km} \mathrm{~s}^{-1} \mathrm{Mpc}^{-1}$.
}

Table 1. Available spectra of IRAS 07598+6508. Column 1: telescope, Col. 2: observed spectral range, Col. 3: exposure time, Col. 4: resolution

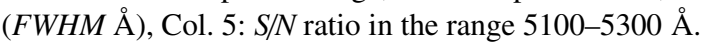

\begin{tabular}{lcccc}
\hline \hline Telescope & Spec. range & Exp. $t .(\mathrm{s})$ & Res. $(\AA)$ & $S / N$ \\
\hline KPNO 4-m & $5590-8220$ & 2700 & 3 & 100 \\
KPNO 2.1-m & $3900-5890$ & 3000 & 7 & 100 \\
KPNO 2.1-m & $5830-7810$ & 2400 & 7 & 100 \\
Keck 10-m & $3800-8900$ & 2400 & 10 & 180 \\
Bok 2.3-m & $4500-8000$ & 6400 & 12 & 600 \\
\hline
\end{tabular}

\section{The data}

\subsection{The Keck 10-m telescope spectrum}

A $2400 \mathrm{~s}$ spectrum was obtained on January 28, 1995 with the Keck 10-m telescope on Mauna Kea and the Low Resolution Imaging Spectrograph (LRIS, Oke et al. 1995) and polarimeter combination (Ogle et al. 1999). A 300 groove $\mathrm{mm}^{-1}$ grating with a dispersion of $2.49 \AA$ pixel $^{-1}$ gave a resolution of $10 \AA$. The spectrum covers the observed wavelength range 3800-8900 A. The detector was a $2048 \times 204824 \mu$ m pixel Tektronix CCD.

\subsection{The KPNO 4-m telescope spectrum}

A $2700 \mathrm{~s}$ spectrum was obtained on February 1, 1991 with the KPNO 4-m telescope and the RC spectrograph 
(Boroson \& Meyers 1992). The detector was a thick Tektronics $2048 \times 204821 \mu \mathrm{m}$ pixel CCD. A 600 grooves $\mathrm{mm}^{-1}$ grating was used in first order, giving a dispersion of about $1.3 \AA$ pixel $^{-1}$. The spectral coverage was $2630 \AA$ (5590-8220 $\mathrm{A})$. A slit width of $225 \mu \mathrm{m}$, corresponding to about $1^{\prime \prime} .5$, was used. This projected on the CCD to a $F W H M$ of 2.3 pixels or $3.0 \AA$ as measured from comparison lines. Spectrophotometric standards were observed. These star observations were used for removal of atmospheric features as well as flux calibration.

\subsection{The 2.3-m Bok telescope spectrum}

A 6400 s spectrum was obtained on November 18, 1995 with the 2.3-m Bok telescope on Kitt Peak and the spectropolarimeter described by Schmidt et al. (1992). It has been published by Schmidt \& Hines (1999). The detector was a $800 \times 1200$ $15 \mu \mathrm{m}$ pixel Loral CCD. A 600 grooves $\mathrm{mm}^{-1}$ grating was used. A spectral coverage of about 4500-8000 ^ was obtained. A slit width of $3^{\prime \prime}$ was used. The spectral resolution was $\sim 12 \AA$. Spectrophotometric standards were observed. These star observations were used for flux calibration.

\subsection{The KPNO 2.1-m telescope spectra}

Two spectra were obtained on February 15, 1991 with the KPNO 2.1-m telescope and the Gold spectrograph. The detector was a TI $800 \times 80015 \mu \mathrm{m}$ pixel CCD. The observations were made using a 300 grooves $\mathrm{mm}^{-1}$ grating. The blue spectrum was exposed for $2 \times 1500 \mathrm{~s}$. It covers the range $3900-5890 \AA$. The red spectrum was exposed for $2 \times 1200 \mathrm{~s}$ and covers the range 5830-7810 ̊. The resolution was 6.5-7.0 ̊. These spectra were published by Lipari et al. (1993) and Lipari (1994).

\section{Analysis}

\subsection{Line fitting}

All spectra have been deredshifted using $z=0.149$. The lines were fit using a code originally written by E. Zuiderwijk and described in Véron et al. (1980).

We started by fitting the Keck spectrum, which has the largest spectral range of all available spectra, although it does not have the best spectral resolution nor the best $S / N$ ratio. We used only the spectral range 3450-6960 $\AA$, the red end of the spectrum being noisy. We masked the range 6610-6680 $\AA$ which is affected by the atmospheric $\mathrm{A}$ band. The other three spectra were then fit with the same set of emission lines.

Initially, Gaussian profiles were adopted. To get a good fit three emission line systems with different line velocity and width were required: a very weak narrow line (NLR), a broad line (BLR) and a very broad line (VBLR) systems. In each system all the lines were forced to have a Gaussian profile with the same velocity and width. The resulting low value of the BLR FWHM, $\sim 1780 \mathrm{~km} \mathrm{~s}^{-1}$, qualifies this object to be classified as a NLS1.

However, one difficulty with this fit is that a few of the strongest emission lines from Fe II multiplets 27, 42 and 49 (especially m. $42 \lambda 5018$ and $\lambda 5169)$ appear to have a narrow core $\left(1080 \mathrm{~km} \mathrm{~s}^{-1} F W H M\right)$ at the velocity of the broad line system (Fig. 1).

As Véron-Cetty et al. (2001) have shown that the broad emission lines of NLS1s are better fit with Lorentzians than with Gaussian profiles, we repeated the fitting process using Gaussian profiles for the VBLR and Lorentzians for the BLR. This fit

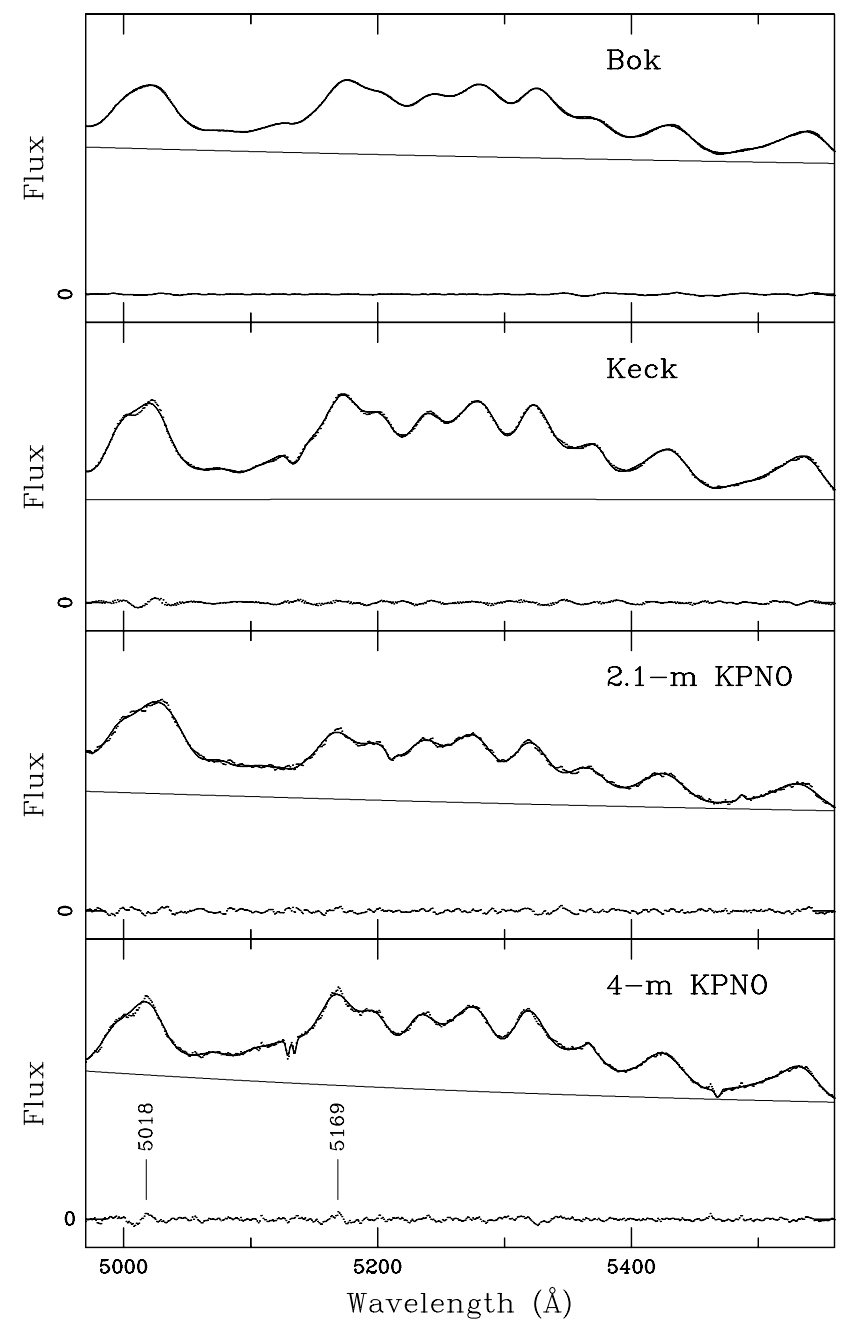

Fig. 1. The deredshifted spectra of IRAS $07598+6508$ in the range $\lambda \lambda 4970-5570$, with the fits, the continua and the residuals. The positions of the Fe II $42 \lambda 5018$ and $\lambda 5169$ lines are shown. The residuals of the 4-m KPNO spectrum at these positions are large, probably indicating that the profile of these lines is not trully Gaussian (see text).

was not satisfactory as the continuum was unacceptably low, especially in the region $\lambda \lambda 5600-5800 \AA$ where few emission lines are expected. This is due to the fact that the BLR spectrum contains a large number of lines. Lorentzian profiles have extended wings; the addition of the wings of all these lines produces a pseudo continuum which pushes down the true continuum. It is possible that the true profiles could be Lorentzians with truncated wings, as very high velocity extensions of the emitting clouds are unlikely (there is no reason to believe that the line profile is strictly Lorentzian or Gaussian). To test this hypothesis, we fit the BLR Balmer lines and the strongest metallic lines with Lorentzians and the other with Gaussians, with all lines of this system having the same central velocity. The resulting fit is very similar to the one obtained with Gaussians only, except for two differences: a) the NLR has vanished which suggests that it is not real and b) the narrow core in the strongest metallic lines has disappeared.

Using only Gaussian profiles, we obtained the following results:

$1 /$ The BLR has a $F W H M \sim 1780 \mathrm{~km} \mathrm{~s}^{-1}$. In addition a second component was needed to fit the $\mathrm{H} \alpha$ line. This additional component is blueshifted by $\sim 1300 \mathrm{~km} \mathrm{~s}^{-1}$ with respect to the 


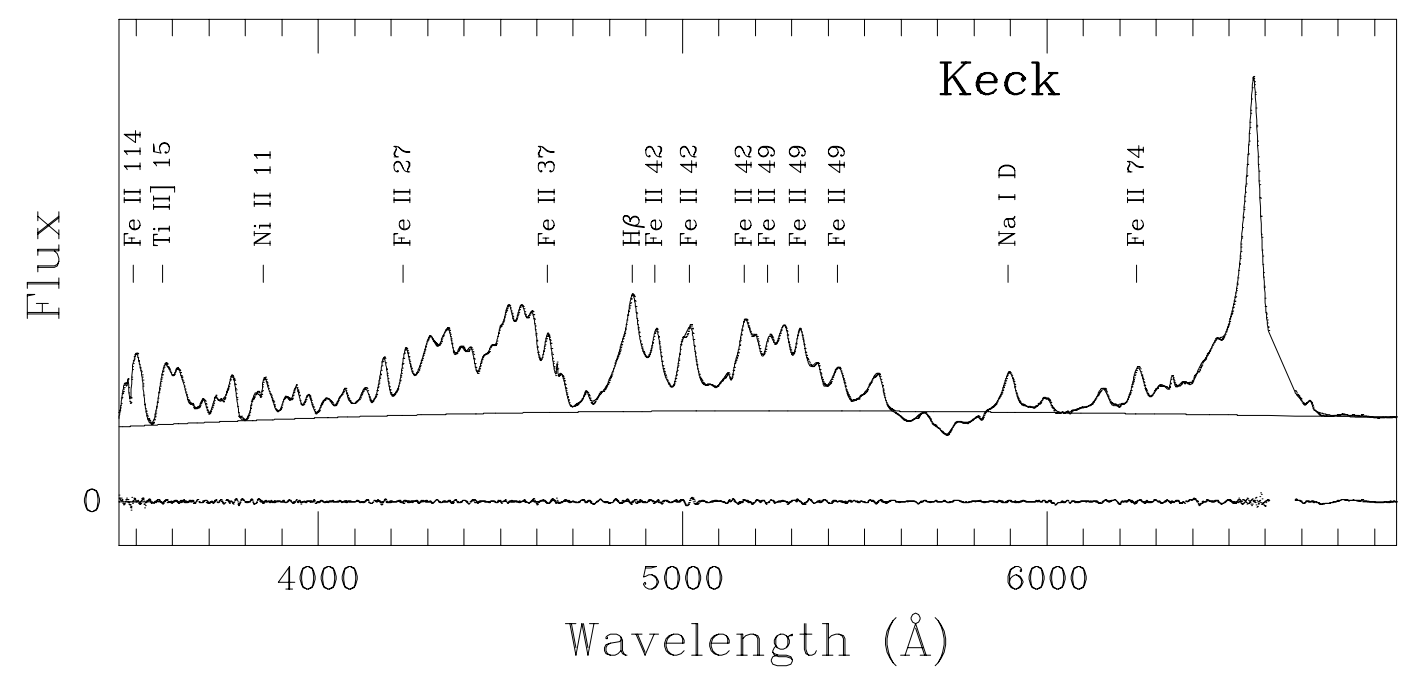

Fig. 2. The deredshifted Keck spectrum of IRAS $07598+6508$ with the fit, the continuum and the residuals. The strongest emission lines have been identified.

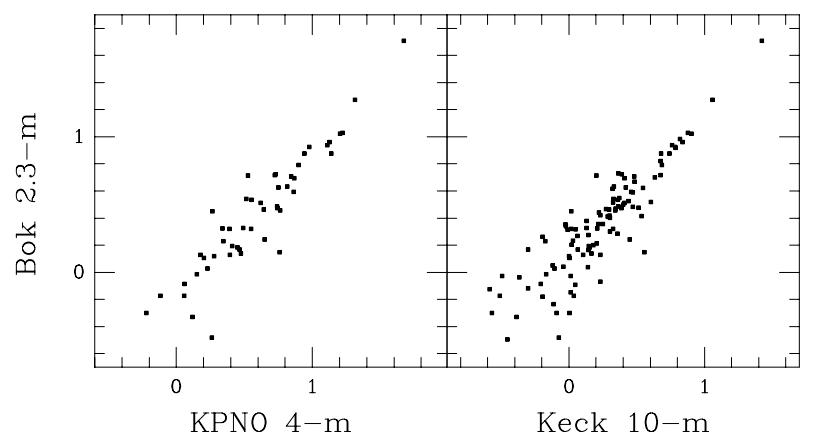

Fig. 3. Plot of the logarithm of the relative peak intensity of the detected lines in the Bok 2.3-m spectrum vs. the corresponding values in the KPNO 4-m and Keck 10-m spectra respectively.

main component and has a $F W H M$ of $\sim 1000 \mathrm{~km} \mathrm{~s}^{-1}$. Its flux is equal to $\sim 7 \%$ of the flux of the stronger component. Boroson $\&$ Meyers (1992) have shown that the BALQSOs have an $\mathrm{H} \alpha$ line with a large blue asymmetry similar to the one observed here.

The FWHM of the $\mathrm{H} \alpha$ line in the BLR has been estimated to be $2550 \mathrm{~km} \mathrm{~s}^{-1}$ (Boroson \& Meyers 1992) and that of $\mathrm{H} \beta$ $3200 \mathrm{~km} \mathrm{~s}^{-1}$ (Lipari et al. 1993), $3150 \mathrm{~km} \mathrm{~s}^{-1}$ (Zheng et al. 2002) or even $4850 \mathrm{~km} \mathrm{~s}^{-1}$ (Marziani et al. 2003). The significantly smaller width found here may be attributed to the identification of a very broad component. The quoted values must refer to the complex profile made of the two broad components.

2/ The VBLR ( 7500 $\left.\mathrm{km} \mathrm{s}^{-1} F W H M\right)$ is blueshifted by $\sim 760 \mathrm{~km} \mathrm{~s}^{-1}$ with respect to the BLR. Its flux is about three times larger than that of the BLR. Note that the parameters of this component are rather poorly determined due to the presence of the atmospheric $\mathrm{A}$ band in the $\mathrm{H} \alpha$ red wing. Such a VBLR seems to be common in QSOs, blueshifted by $\geq 1000 \mathrm{~km} \mathrm{~s}^{-1}$, with a width $\geq 7000 \mathrm{~km} \mathrm{~s}^{-1}$ (Brotherton et al. 1994).

Figure 3 shows plots of the logarithm of the relative peak intensity of all detected lines in the Bok 2.3-m spectrum vs. the corresponding values in the KPNO 4-m and Keck 10-m spectra respectively. It appears that the accuracy is of the order of $20 \%$ for the strongest lines and about a factor of 2 for the weakest.

The best fit of the Keck spectrum is shown in Fig. 2.

The $\mathrm{P} \alpha$ line shows a blueshifted broad component (FWHM $\left.3900 \mathrm{~km} \mathrm{~s}^{-1}\right)$ together with a narrow core $\left(F W H M \sim 530 \mathrm{~km} \mathrm{~s}^{-1}\right)$
(Taniguchi et al. 1994). The broad component could be produced by both the BLR and the VBLR.

Hines \& Wills (1995) found that the peaks of the highionization UV lines are blueshifted with respect to the $\mathrm{H} \alpha$ and $\mathrm{NaID} \lambda 5892$ emission peaks by $3000 \mathrm{~km} \mathrm{~s}^{-1}$. It is difficult to associate these lines with any of the three systems listed above as none of them have such a large blueshift with respect to the broad line system.

\subsection{The emission spectrum}

\subsubsection{No narrow line component (NLR)?}

As shown above, the weak narrow line component may not be real, in agreement with Boroson \& Meyers (1992). However weak [O III] lines have been observed with $\lambda 5007 / \mathrm{H} \beta \sim 0.02$ by Lipari (1994).

\subsubsection{The broad line component (BLR)}

Due to the large number of emission lines and their substantial width, most of them are heavily blended. Consequently, it is impossible to identify them all unambiguously. Therefore, our process relies on some preconceived ideas. As it is well known that Fe II is an important contributor, we have included in our model all the strongest Fe II lines appearing in high density, high optical thickness models. Such line lists can be obtained by running the code CLOUDY with the large $\mathrm{Fe}^{+}$atom (Ferland 2002).

As the ionisation potentials of $\mathrm{Fe}, \mathrm{Ti}$ and $\mathrm{Cr}$ are very similar $(6.8-7.8 \mathrm{eV}$ for the neutral atoms and $13.6-18.4 \mathrm{eV}$ for the once ionized ions), lines of all these elements are expected to be present. It is indeed the case in the spectrum of the very peculiar star XX Ophiuci (Merrill 1951, 1961; Cool et al. 2005) nicknamed the "iron star" by Merrill (1924). Therefore, we include in our analysis all lines of these elements observed in the spectrum of XX Oph.

It turns out that most of the multiplets of Fe II, Ti II and Cr II observed in XXOph are indeed present in the spectrum of IRAS $07598+6508$ (they are listed in Tables 2-4, for Fe II, Ti II and $\mathrm{Cr}$ II respectively). Two emission features could not be identified (at $\lambda 5051$ and 26339 ).

In addition to these metallic lines, the Balmer lines $(\mathrm{H} \alpha$ to $\mathrm{H} \delta$ ), Ca II $\lambda \lambda 3933,3968$ and Na I D $\lambda \lambda 5890,5896$ are present. 
Table 2. Observed permitted Fe II multiplets in the spectrum of IRAS 07598+6508. Column 1: multiplet number, Col. 2: transition, Col. 3: upper level energy, Col. 4: number of observed lines/number of lines in the multiplet in the observed spectral range.

\begin{tabular}{|c|c|c|c|}
\hline m. & Transition & u.1. (eV) & \\
\hline 3 & $\mathrm{a}^{4} \mathrm{P}-\mathrm{z}^{6} \mathrm{D}^{\mathrm{o}}$ & 4.80 & $1 / 8$ \\
\hline 11 & $\mathrm{a}^{2} \mathrm{P}-\mathrm{z}^{6} \mathrm{D}^{\mathrm{o}}$ & 4.80 & $1 / 1$ \\
\hline 24 & $b^{4} P-z^{6} D^{o}$ & 4.80 & $1 / 8$ \\
\hline 34 & $b^{4} \mathrm{~F}-\mathrm{z}^{6} \mathrm{D}^{0}$ & 4.80 & $3 / 4$ \\
\hline 40 & $a^{6} S-z^{6} D^{o}$ & 4.80 & $3 / 3$ \\
\hline 12 & $\mathrm{a}^{2} \mathrm{P}-\mathrm{z}^{6} \mathrm{~F}^{\mathrm{o}}$ & 5.23 & $1 / 5$ \\
\hline 17 & $\mathrm{a}^{2} \mathrm{H}-\mathrm{z}^{6} \mathrm{~F}^{\mathrm{o}}$ & 5.23 & $1 / 5$ \\
\hline 25 & $\mathrm{~b}^{4} \mathrm{P}-\mathrm{z}^{6} \mathrm{~F}^{\mathrm{o}}$ & 5.23 & $6 / 8$ \\
\hline 35 & $\mathrm{~b}^{4} \mathrm{~F}-\mathrm{z}^{6} \mathrm{~F}^{\mathrm{o}}$ & 5.23 & $9 / 12$ \\
\hline 41 & $a^{6} S-z^{6} F^{o}$ & 5.23 & $2 / 3$ \\
\hline 46 & $\mathrm{a}^{4} \mathrm{G}-\mathrm{z}^{6} \mathrm{~F}^{\mathrm{o}}$ & 5.23 & $6 / 11$ \\
\hline 26 & $\mathrm{~b}^{4} \mathrm{P}-\mathrm{z}^{6} \mathrm{P}^{\mathrm{o}}$ & 5.34 & $4 / 6$ \\
\hline 31 & $a^{4} H-z^{6} P^{o}$ & 5.34 & $1 / 3$ \\
\hline 36 & $\mathrm{~b}^{4} \mathrm{~F}-\mathrm{z}^{6} \mathrm{P}^{\mathrm{o}}$ & 5.34 & $5 / 5$ \\
\hline 42 & $a^{6} S-z^{6} P^{o}$ & 5.34 & $3 / 3$ \\
\hline 47 & $\mathrm{a}^{4} \mathrm{G}-\mathrm{z}^{6} \mathrm{P}^{\mathrm{o}}$ & 5.34 & $1 / 3$ \\
\hline 21 & $\mathrm{a}^{2} \mathrm{D}-\mathrm{z}^{4} \mathrm{D}^{\mathrm{o}}$ & 5.56 & $4 / 6$ \\
\hline 27 & $\mathrm{~b}^{4} \mathrm{P}-\mathrm{z}^{4} \mathrm{D}^{\mathrm{o}}$ & 5.56 & $8 / 8$ \\
\hline 33 & $\mathrm{a}^{4} \mathrm{H}-\mathrm{z}^{4} \mathrm{D}^{\mathrm{o}}$ & 5.56 & $1 / 3$ \\
\hline 38 & $b^{4} F-z^{4} D^{o}$ & 5.56 & $8 / 9$ \\
\hline 43 & $a^{6} S-z^{4} D^{0}$ & 5.56 & $2 / 3$ \\
\hline 48 & $a^{4} G-z^{4} D^{o}$ & 5.56 & $5 / 6$ \\
\hline 56 & $\mathrm{~b}^{2} \mathrm{H}-\mathrm{z}^{4} \mathrm{D}^{\mathrm{o}}$ & 5.56 & $1 / 1$ \\
\hline 28 & $\mathrm{~b}^{4} \mathrm{P}-\mathrm{z}^{4} \mathrm{~F}^{\mathrm{o}}$ & 5.57 & $6 / 6$ \\
\hline 32 & $\mathrm{a}^{4} \mathrm{H}-\mathrm{z}^{4} \mathrm{~F}^{o}$ & 5.57 & $5 / 6$ \\
\hline 37 & $\mathrm{~b}^{4} \mathrm{~F}-\mathrm{z}^{4} \mathrm{~F}^{\mathrm{o}}$ & 5.57 & $10 / 10$ \\
\hline 44 & $a^{6} S-z^{4} F^{o}$ & 5.57 & $1 / 1$ \\
\hline 49 & $\mathrm{a}^{4} \mathrm{G}-\mathrm{z}^{4} \mathrm{~F}^{\mathrm{o}}$ & 5.57 & $9 / 9$ \\
\hline 55 & $\mathrm{~b}^{2} \mathrm{H}-\mathrm{z}^{4} \mathrm{~F}^{\mathrm{o}}$ & 5.57 & $2 / 3$ \\
\hline 16 & $\mathrm{a}^{2} \mathrm{P}-\mathrm{z}^{4} \mathrm{P}^{\mathrm{o}}$ & 5.85 & $2 / 3$ \\
\hline 23 & $\mathrm{a}^{2} \mathrm{D}-\mathrm{z}^{4} \mathrm{P}^{0}$ & 5.85 & $1 / 5$ \\
\hline 29 & $\mathrm{~b}^{2} \mathrm{P}-\mathrm{z}^{4} \mathrm{P}^{\mathrm{o}}$ & 5.85 & $7 / 7$ \\
\hline 74 & $\mathrm{~b}^{4} \mathrm{D}-\mathrm{z}^{4} \mathrm{P}^{\mathrm{o}}$ & 5.85 & $8 / 8$ \\
\hline 148 & $\mathrm{c}^{2} \mathrm{D}-\mathrm{z}^{2} \mathrm{D}^{\mathrm{o}}$ & 7.54 & $1 / 4$ \\
\hline 114 & $\mathrm{c}^{2} \mathrm{G}-\mathrm{z}^{2} \mathrm{G}^{\mathrm{o}}$ & 7.66 & $2 / 4$ \\
\hline 182 & $\mathrm{~d}^{2} \mathrm{D}-\mathrm{z}^{2} \mathrm{P}^{\mathrm{o}}$ & 8.00 & $1 / 3$ \\
\hline
\end{tabular}

Na ID has previously been observed in emission with $E W=$ $9.7 \AA$ (Boroson \& Meyers 1992) and Na ID/H $\alpha \sim 0.05$ (Lipari 1994). We found $E W(\mathrm{NaID})=9.6-10.3 \AA$ and $\mathrm{NaID} / \mathrm{H} \alpha \sim$ $0.16-0.20$, but this ratio uses the flux of the broad $\mathrm{H} \alpha$ component rather than the total $\mathrm{H} \alpha$ flux, which probably explains why we found a much larger value for the $\mathrm{Na} \mathrm{ID} / \mathrm{H} \alpha$ ratio.

Lawrence et al. (1997) found Fe II $\lambda 4570 / \mathrm{H} \beta \sim 2.6$, Lipari et al. (1993) 2.6, Lipari (1994) 2.3, Zheng et al. (2002) 2.75 and Marziani et al. (2003) 1.21. These values are in good agreement, except for the last one which is about twice smaller; however, our value is much larger, on the order of 8 . This is due to the fact that the $\mathrm{H} \beta$ flux in the BLR is only a quarter of the total $\mathrm{H} \beta$ flux as we have seen above. Indeed we compare the $\mathrm{Fe}$ II flux to that of the $\mathrm{H} \beta$ flux coming from the same region, namely the BLR.

A Balmer line ratio $\mathrm{H} \alpha / \mathrm{H} \beta \sim 5-6.2$ was measured, suggesting the presence of reddening in the emission line region (Lipari 1994; Hines \& Wills 1995), although this could be explained by radiative transfer effects in high optical thickness
Table 3. Observed permitted Ti II multiplets in the spectrum of IRAS 07598+6508. Column 1: multiplet number, Col. 2: transition, Col. 3: upper level energy, Col. 4: number of observed lines/number of lines in the multiplet in the observed spectral range.

\begin{tabular}{|c|c|c|c|}
\hline m. & Transition & "u.1. (eV) & \\
\hline $\begin{array}{r}6 \\
11 \\
17\end{array}$ & $\begin{array}{c}\mathrm{b}^{4} \mathrm{~F}-\mathrm{z}^{4} \mathrm{G}^{\mathrm{o}} \\
\mathrm{a}^{2} \mathrm{~F}-\mathrm{z}^{4} \mathrm{G}^{\mathrm{o}} \\
\mathrm{a}^{2} \mathrm{D}-\mathrm{z}^{4} \mathrm{G}^{\mathrm{o}} \\
\mathrm{a}^{4} \mathrm{P}-\mathrm{z}^{4} \mathrm{G}^{\mathrm{o}}\end{array}$ & $\begin{array}{l}3.67 \\
3.67 \\
3.67 \\
3.67 \\
\end{array}$ & $\begin{array}{l}2 / 8 \\
3 / 5 \\
1 / 3 \\
1 / 3 \\
\end{array}$ \\
\hline $\begin{array}{l}12 \\
18 \\
68 \\
80\end{array}$ & $\begin{array}{l}\mathrm{a}^{2} \mathrm{~F}-\mathrm{z}^{4} \mathrm{~F}^{\mathrm{o}} \\
\mathrm{a}^{2} \mathrm{D}-\mathrm{z}^{4} \mathrm{~F}^{\mathrm{o}} \\
\mathrm{b}^{2} \mathrm{D}-\mathrm{z}^{4} \mathrm{~F}^{\mathrm{o}} \\
\mathrm{a}^{2} \mathrm{H}-\mathrm{z}^{4} \mathrm{~F}^{\mathrm{o}}\end{array}$ & $\begin{array}{l}3.84 \\
3.84 \\
3.84 \\
3.84 \\
\end{array}$ & $\begin{array}{l}2 / 6 \\
2 / 5 \\
2 / 5 \\
2 / 3\end{array}$ \\
\hline $\begin{array}{l}13 \\
19 \\
31 \\
69 \\
\end{array}$ & $\begin{array}{l}\mathrm{a}^{2} \mathrm{~F}-\mathrm{z}^{2} \mathrm{~F}^{\mathrm{o}} \\
\mathrm{a}^{2} \mathrm{D}-\mathrm{z}^{2} \mathrm{~F}^{\mathrm{o}} \\
\mathrm{a}^{2} \mathrm{G}-\mathrm{z}^{2} \mathrm{~F}^{\mathrm{o}} \\
\mathrm{b}^{2} \mathrm{D}-\mathrm{z}^{2} \mathrm{~F}^{\mathrm{o}}\end{array}$ & $\begin{array}{l}3.87 \\
3.87 \\
3.87 \\
3.87 \\
\end{array}$ & $\begin{array}{l}2 / 4 \\
3 / 3 \\
3 / 3 \\
1 / 3 \\
\end{array}$ \\
\hline $\begin{array}{l}14 \\
20 \\
40 \\
50 \\
70\end{array}$ & $\begin{array}{c}a^{2} F-z^{2} D^{o} \\
a^{2} D-z^{2} D^{o} \\
a^{4} P-z^{2} D^{o} \\
a^{2} P-z^{2} D^{o} \\
b^{2} D-z^{2} D^{o}\end{array}$ & $\begin{array}{l}3.94 \\
3.94 \\
3.94 \\
3.94 \\
3.94\end{array}$ & $\begin{array}{l}1 / 2 \\
4 / 4 \\
4 / 5 \\
2 / 3 \\
1 / 4\end{array}$ \\
\hline $\begin{array}{l}15 \\
21 \\
41 \\
51 \\
61\end{array}$ & $\begin{array}{l}a^{2} F-z^{4} D^{o} \\
a^{2} D-z^{4} D^{o} \\
a^{4} P-z^{4} D^{o} \\
a^{2} P-z^{4} D^{o} \\
b^{4} P-z^{4} D^{o}\end{array}$ & $\begin{array}{l}4.04 \\
4.04 \\
4.04 \\
4.04 \\
4.04 \\
\end{array}$ & $\begin{array}{l}5 / 5 \\
3 / 6 \\
7 / 8 \\
3 / 5 \\
5 / 8 \\
\end{array}$ \\
\hline $\begin{array}{l}34 \\
82\end{array}$ & $\begin{array}{l}a^{2} G-z^{2} G^{\circ} \\
a^{2} H-z^{2} G^{o}\end{array}$ & $\begin{array}{l}4.26 \\
4.26\end{array}$ & $\begin{array}{l}1 / 4 \\
2 / 3\end{array}$ \\
\hline $\begin{array}{l}52 \\
92\end{array}$ & $\begin{array}{l}a^{2} \mathrm{P}-\mathrm{z}^{2} \mathrm{~S}^{\mathrm{o}} \\
\mathrm{b}^{2} \mathrm{P}-\mathrm{z}^{2} \mathrm{~S}^{\mathrm{o}}\end{array}$ & $\begin{array}{l}4.64 \\
4.64\end{array}$ & $\begin{array}{l}1 / 2 \\
1 / 2\end{array}$ \\
\hline $\begin{array}{l}72 \\
93\end{array}$ & $\begin{array}{l}b^{2} \mathrm{D}-\mathrm{y}^{2} \mathrm{D}^{\mathrm{o}} \\
\mathrm{b}^{2} \mathrm{P}-\mathrm{y}^{2} \mathrm{D}^{\mathrm{o}}\end{array}$ & $\begin{array}{l}4.85 \\
4.85\end{array}$ & $\begin{array}{l}2 / 4 \\
2 / 3\end{array}$ \\
\hline 94 & $\mathrm{~b}^{2} \mathrm{P}-\mathrm{z}^{2} \mathrm{P}^{\mathrm{o}}$ & 4.89 & $3 / 4$ \\
\hline $\begin{array}{l}75 \\
87\end{array}$ & $\begin{array}{l}b^{2} D-y^{2} F^{o} \\
b^{2} G-y^{2} F^{o}\end{array}$ & $\begin{array}{l}4.94 \\
4.94\end{array}$ & $\begin{array}{l}2 / 3 \\
2 / 3\end{array}$ \\
\hline 76 & $b^{2} D-y^{4} D^{o}$ & 5.04 & $3 / 6$ \\
\hline 104 & $\mathrm{~b}^{2} \mathrm{~F}-\mathrm{y}^{2} \mathrm{G}^{\mathrm{o}}$ & 5.42 & $2 / 3$ \\
\hline $\begin{array}{l}105 \\
113\end{array}$ & $\begin{array}{l}b^{2} F-x^{2} D^{o} \\
c^{2} D-x^{2} D^{o}\end{array}$ & $\begin{array}{l}5.57 \\
5.57\end{array}$ & $\begin{array}{l}3 / 3 \\
1 / 4\end{array}$ \\
\hline $\begin{array}{r}99 \\
114\end{array}$ & $\begin{array}{l}\mathrm{b}^{2} \mathrm{P}-\mathrm{y}^{2} \mathrm{P}^{\mathrm{o}} \\
\mathrm{c}^{2} \mathrm{D}-\mathrm{y}^{2} \mathrm{P}^{\mathrm{o}}\end{array}$ & $\begin{array}{l}5.62 \\
5.62\end{array}$ & $\begin{array}{l}1 / 3 \\
2 / 3\end{array}$ \\
\hline 115 & $\mathrm{c}^{2} \mathrm{D}-\mathrm{x}^{2} \mathrm{~F}^{\mathrm{o}}$ & 5.42 & $2 / 3$ \\
\hline
\end{tabular}

media (Collin-Souffrin et al. 1982). For the BLR we found that this ratio is $\sim 6.3$. The spectral energy distribution is not reddened and matches that of typical QSOs (Hines \& Wills 1995).

The list of all lines detected in the BLR in each of the four available spectra is given in Appendix A. All these lines have been fit with a Gaussian profile having the same velocity width $\left(1780 \mathrm{~km} \mathrm{~s}^{-1} F W H M\right)$.

\subsubsection{The very broad line component (VBLR)}

From this region, we detect only the Balmer lines from $\mathrm{H} \alpha$ to $\mathrm{H} \delta$.

\subsection{The Na I D absorption}

A narrow $\mathrm{NaID}$ doublet has been seen in absorption at an outflow velocity of $3800 \mathrm{~km} \mathrm{~s}^{-1}$ and $E W=0.95 \AA$ 
Table 4. Observed permitted CrII multiplets in the spectrum of IRAS 07598+6508. Column 1: multiplet number, Col. 2: transition, Col. 3: upper level energy, Col. 4: number of observed lines/number of lines in the multiplet.

\begin{tabular}{rccc}
\hline \hline $\mathrm{m}$. & Transition & u.l. $(\mathrm{eV})$ & \\
\hline 1 & $\mathrm{a}^{4} \mathrm{D}-\mathrm{z}^{6} \mathrm{~F}^{\circ}$ & 5.86 & $1 / 11$ \\
\hline 2 & $\mathrm{a}^{4} \mathrm{D}-\mathrm{z}^{6} \mathrm{P}^{\mathrm{o}}$ & 6.00 & $1 / 8$ \\
\hline 12 & $\mathrm{a}^{4} \mathrm{P}-\mathrm{z}^{4} \mathrm{P}^{\mathrm{o}}$ & 6.09 & $7 / 7$ \\
\hline 19 & $\mathrm{~b}^{4} \mathrm{D}-\mathrm{z}^{6} \mathrm{D}^{\circ}$ & 6.15 & $3 / 11$ \\
29 & $\mathrm{a}^{4} \mathrm{~F}-\mathrm{z}^{6} \mathrm{D}^{\circ}$ & 6.15 & $1 / 11$ \\
\hline 20 & $\mathrm{~b}^{4} \mathrm{D}-\mathrm{z}^{4} \mathrm{~F}^{\circ}$ & 6.41 & $1 / 9$ \\
30 & $\mathrm{a}^{4} \mathrm{~F}-\mathrm{z}^{4} \mathrm{~F}^{\circ}$ & 6.41 & $3 / 10$ \\
50 & $\mathrm{~b}^{4} \mathrm{G}-\mathrm{z}^{4} \mathrm{~F}^{\circ}$ & 6.41 & $4 / 7$ \\
\hline 26 & $\mathrm{~b}^{4} \mathrm{P}-\mathrm{z}^{4} \mathrm{D}^{\circ}$ & 6.76 & $1 / 7$ \\
31 & $\mathrm{a}^{4} \mathrm{~F}-\mathrm{z}^{4} \mathrm{D}^{\circ}$ & 6.76 & $4 / 9$ \\
44 & $\mathrm{~b}^{4} \mathrm{~F}-\mathrm{z}^{4} \mathrm{D}^{\circ}$ & 6.76 & $6 / 9$ \\
\hline 117 & $\mathrm{~b}^{2} \mathrm{G}-\mathrm{z}^{4} \mathrm{G}^{\circ}$ & 8.07 & $2 / 3$ \\
\hline
\end{tabular}

(Boroson \& Meyers 1992). It is clearly seen at that velocity and strength in the KPNO 4-m spectrum. Rupke et al. (2005) have observed this doublet at $V=-3939 \pm 10 \mathrm{~km} \mathrm{~s}^{-1}$, with $F W H M=$ $130 \mathrm{~km} \mathrm{~s}^{-1}$.

In addition, a broad absorption trough is seen from about $\lambda 5550 \AA$ to about $\lambda 5800 \AA$ in the object rest frame, corresponding to outflow velocities from the narrow system up to about $16000 \mathrm{~km} \mathrm{~s}^{-1}$ (Boroson \& Meyers 1992). We have modelled this broad absorption feature with four Gaussians blueshifted by $14630,11300,9400$ and $6340 \mathrm{~km} \mathrm{~s}^{-1}$, having FWHMs of 2900 , 1250,2360 and $3100 \mathrm{~km} \mathrm{~s}^{-1}$ and $E W$ s of 5.9, 2.2, 10.0 and $7.9 \AA$ respectively. The general pattern of the absorption is quite similar to what is seen in Mg II (Lipari 1994). Strong high-ionization BALs have also been observed in this object (Lipari 1994; Turnshek et al. 1997).

The profile of the broad absorption feature appears quite similar in the four spectra we have analysed, taken in 1991 and 1995. However, Rupke et al. have obtained on April 13, 2004 a high $S / N$ ratio spectrum with the KPNO 4-m telescope (5400 s exposure), with a resolution of $85 \mathrm{~km} \mathrm{~s}^{-1}$. The profile of the absorption feature is quite different in that spectrum; the bluest $\left(-14630 \mathrm{~km} \mathrm{~s}^{-1}\right)$ and the reddest $\left(-6340 \mathrm{~km} \mathrm{~s}^{-1}\right)$ components have completely disappeared.

A Galactic Na I D doublet is present with an $E W$ of $0.65 \AA$.

\section{Discussion}

\subsection{The theoretical Fe Il emission spectrum}

Baldwin et al. (2004) showed that photoionized BELR clouds cannot produce both the observed shape and equivalent width of the 2200-2800 $\AA$ Fe II UV bump in active galactic nuclei, unless there is a considerable velocity structure corresponding to a microturbulent velocity parameter $v_{\text {turb }}>100 \mathrm{~km} \mathrm{~s}^{-1}$ for the emitting cloud. An alternative solution is that the Fe II emission is the result of collisional excitation in a warm, dense gas. However, they show that gas with temperature $6000 \mathrm{~K}<T<$ $40000 \mathrm{~K}$, density $n_{\mathrm{H}} \sim 10^{12}-10^{16} \mathrm{~cm}^{-3}$ and column density $N_{\mathrm{H}} \sim 10^{25} \mathrm{~cm}^{-2}$ will emit primarily Fe II UV lines. Since this gas does not emit strongly in lines of other elements, it would have to constitute another component in an already complicated picture of the BELR and consequently these authors prefer the model involving turbulence.
We will show here that photoionization models are actually not able to explain the observed emission lines of IRAS $07598+6508$, while some hope arises from purely collisional models.

Using the code CLOUDY with its large $\mathrm{Fe}^{+}$atom (Ferland 2002) we computed a number of models to match the observed Fe II spectrum and the main BLR features. Unfortunately CLOUDY does not provide information on TiII, Ni II or Cr II optical lines. The intensity of the Fe II predicted lines can be obtained either separately or summed over wavelength bands directly comparable to the observations.

The discussion is summarized in Table 5, which gives in the first column the main features observed in the BLR, in Col. 2 the wavelength of the lines or the wavelength range for the Fe II bands, in Cols. 3-6 the line intensity ratios referred to $\mathrm{H} \beta$ measured in the four available spectra, and in the last five columns the results from different models. For each of these models several attempts have been made to reproduce the observations, but we only give here the best fits.

Our first attempt was to compute a standard photoionization model, assuming that the size of the emission region follows the relationship between the size of the BLR and the luminosity of the central source of radiation deduced by Kaspi et al. (2000) from reverberation mapping of a sample of AGN. Assuming an optical luminosity $\sim 10^{45} \mathrm{erg} \mathrm{s}^{-1}$, we infer a distance of the BLR from the central source of radiation of $\sim 4 \times 10^{17} \mathrm{~cm}$. The results of a model with a density $n=10^{12} \mathrm{~cm}^{-3}$ and a column density $N_{\mathrm{H}}=2 \times 10^{23} \mathrm{~cm}^{-2}$, values commonly adopted for the BLR, are given in Col. 7 of Table 5 (model 1). It clearly shows some problems: the excess strength of the predicted He I, Ly $\alpha$, $\mathrm{Mg}$ II and Balmer continuum, as well as the weakness of the Fe II features. The former lines are formed in the H II region of the irradiated cloud, but no such strong features are observed in the UV spectrum of IRAS 07598+6508 (cf. Lanzetta et al. 1993 and Lipari 1994) or of any AGN, and no He I $\lambda 5876$ is identified in any of the four optical spectra.

A way to weaken the influence of the HII region is to locate the BLR farther away from the central source. A distance as large as $3 \times 10^{19} \mathrm{~cm}$ is needed to lower the $\mathrm{He} \mathrm{I} \lambda 5876 / \mathrm{H} \beta$ ratio down to 0.2 . Such a model has the disadvantage of not producing enough Fe II emission in addition of being difficult to explain in term of the location of the BLR.

Putting aside this distance problem for a while, it is possible to strengthen the emission of the excited $\mathrm{HI}^{*}$ region if an additional heating mechanism, such as a mechanical one, is at work. The results of such a model are given in Col. 8 (model 2), where the additional heating is assumed to be of the order of the bolometric luminosity $\left(H_{\text {extra }}=6 \times 10^{45} \mathrm{erg} \mathrm{s}^{-1}\right)$. Although it reproduces the overall Fe II intensity, the line ratios are not in agreement with the observed ones; this is, in particular, the case for $\mathrm{Mg}$ II which, in this model, is inconsistent with the observations.

An increase of the density of the medium up to $10^{14} \mathrm{~cm}^{-3}$, as proposed in Col. 9 (model 3), produces a substantial decrease of $\mathrm{Mg}$ II but also worsens the match to the Ca II and Na ID line intensities. Note however that high densities not only produce Fe II line ratios in good agreement with the observations, but also allow the BLR to be located closer to the central source, necessitating however a very strong contribution from mechanical heating.

Faced with the undeniable difficulties of the models where the primary source of excitation is radiative - even if the addition of another source of heating improves the result we turned to purely collisional models, i.e. models where the 
Table 5. Observed and computed line ratios in IRAS 07598+6508. A “-" indicates that the line is outside the spectral range or in a region of the spectrum masked because of the presence of poorly corrected atmospheric features.

\begin{tabular}{|c|c|c|c|c|c|c|c|c|c|c|}
\hline$\overline{\text { Lines }}$ & $\bar{\lambda}$ & Keck & $\begin{array}{r}\text { KPNO } \\
4 \mathrm{~m}\end{array}$ & $\begin{array}{r}\text { KPNO } \\
2.1 \mathrm{~m}\end{array}$ & $\begin{array}{r}\text { Bok } \\
2.3 \mathrm{~m}\end{array}$ & 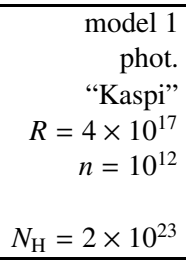 & 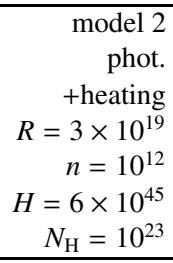 & $\begin{array}{r}\text { model } 3 \\
\text { phot. } \\
\text { +heating } \\
R=5 \times 10^{18} \\
n=10^{14} \\
H=2 \times 10^{46} \\
N_{\mathrm{H}}=5 \times 10^{23} \\
\end{array}$ & $\begin{array}{r}\text { model } 4 \\
\text { coll. } \\
\\
f=3 \% \\
n=10^{15} \\
H=6 \times 10^{44} \\
N_{\mathrm{H}}=10^{24} \\
\end{array}$ & $\begin{array}{r}\text { model } 5 \\
\text { coll. } \\
v=100 \\
f=5 \% \\
n=10^{15} \\
H=6 \times 10^{44} \\
N_{\mathrm{H}}=10^{25}\end{array}$ \\
\hline $\mathrm{H} \alpha$ & & 5.86 & 6.71 & 4.28 & 8.18 & 3.25 & 7.83 & 4.5 & 0.34 & 0.12 \\
\hline $\mathrm{H} \beta$ & & 1.00 & 1.00 & 1.00 & 1.00 & 1.00 & 1.00 & 1.00 & 0.01 & 0.02 \\
\hline $\mathrm{H} \gamma$ & & 0.29 & - & 0.28 & 0.21 & 0.52 & 0.53 & 0.37 & 0.00 & 0.00 \\
\hline $\mathrm{H} \delta$ & & 0.15 & - & 0.07 & 0.08 & 0.40 & 0.36 & 0.18 & 0.00 & 0.00 \\
\hline Ca IIK & 3934 & 0.22 & - & 0.28 & - & 0.63 & 2.76 & 16.5 & 1.34 & 0.88 \\
\hline $\mathrm{Ca}$ IIH & 3969 & 0.19 & - & 0.29 & 0.14 & 0.46 & 2.05 & 14.7 & 1.28 & 0.78 \\
\hline $\mathrm{He} \mathrm{I}$ & 5876 & 0.00 & 0.00 & 0.00 & 0.00 & 2.62 & 0.21 & 0.19 & 0.00 & 0.00 \\
\hline $\mathrm{NaI}$ & 5892 & 0.87 & 1.00 & 0.75 & 1.00 & 0.18 & 6.60 & 10.9 & 0.65 & 0.50 \\
\hline Fe II & & & & & & & & & & \\
\hline 3590 & $3400-3780$ & $>1.57$ & - & 1.35 & - & 0.60 & 4.19 & 5.91 & 6.04 & 6.32 \\
\hline 3910 & $3780-4040$ & 1.23 & - & 1.54 & - & 0.74 & 6.71 & 11.5 & 5.62 & 5.84 \\
\hline 4060 & $4040-4080$ & 0.19 & - & 0.10 & 0.11 & 0.01 & 0.02 & 0.03 & 0.13 & 0.16 \\
\hline 4255 & $4080-4430$ & 5.64 & - & 6.57 & 5.24 & 0.60 & 28.3 & 6.51 & 7.40 & 7.52 \\
\hline 4570 & $4430-4685$ & 7.91 & - & 8.59 & 7.89 & 0.84 & 10.0 & 9.49 & 8.00 & 8.00 \\
\hline 4743 & $4685-4800$ & 0.21 & - & 0.91 & 0.29 & 0.03 & 2.22 & 0.51 & 0.49 & 0.48 \\
\hline 4855 & $4800-4910$ & 1.27 & - & 2.48 & 1.44 & 0.07 & 6.68 & 1.86 & 1.09 & 1.12 \\
\hline 4975 & $4910-5040$ & 4.23 & $>3.12$ & 7.49 & 4.04 & 0.52 & 9.76 & 4.90 & 1.42 & 1.44 \\
\hline 5070 & $5040-5100$ & 0.00 & 0.00 & 0.00 & 0.00 & 0.02 & 0.55 & 0.34 & 0.27 & 0.28 \\
\hline 5143 & $5100-5185$ & 3.26 & 4.60 & 3.31 & 3.16 & 0.28 & 11.0 & 3.68 & 2.18 & 2.32 \\
\hline 5318 & $5185-5450$ & 8.20 & 11.69 & 8.82 & 8.80 & 0.65 & 19.1 & 7.11 & 5.19 & 5.36 \\
\hline 5540 & $5450-5630$ & 0.80 & 1.07 & 0.65 & 0.88 & 0.09 & 3.01 & 1.24 & 1.03 & 1.04 \\
\hline 5865 & $5630-6100$ & 0.77 & 0.62 & 0.58 & 0.09 & 0.10 & 1.65 & 1.92 & 1.39 & 1.44 \\
\hline 6265 & $6100-6430$ & 3.93 & 4.46 & 4.79 & 3.50 & 0.12 & 0.68 & 1.86 & 2.25 & 2.32 \\
\hline 6565 & $6430-6700$ & 1.15 & 1.98 & 4.79 & 1.79 & 0.25 & 2.55 & 4.55 & 1.77 & 1.84 \\
\hline 6910 & $6700-7120$ & 0.00 & - & - & - & 0.02 & 0.49 & 0.03 & 0.12 & 0.12 \\
\hline 7445 & $7120-7770$ & - & - & - & - & 0.15 & 6.47 & 1.73 & 2.69 & 2.72 \\
\hline $\mathrm{L} \alpha$ & 1216 & - & - & - & - & 34.4 & 37.0 & 1.2 & 0.0 & 1.12 \\
\hline Fe II 2355 & $2280-2430$ & - & - & - & - & 4.1 & 21.0 & 15.4 & 11.6 & 6.48 \\
\hline Mg II & 2800 & - & - & - & - & 11.4 & 198.0 & 13.3 & 1.44 & 1.20 \\
\hline $\mathrm{BaC}$ & $<3646$ & - & - & - & - & 55.5 & 2.7 & 1.0 & 0.04 & 0.03 \\
\hline CaII T & 8500 & - & - & - & - & 1.4 & 11.8 & 48.0 & 2.96 & 3.68 \\
\hline
\end{tabular}

emission region is shielded from the central source of radiation and where the source of excitation is only due to mechanical heating. Mechanical heating was first proposed by CollinSouffrin (1986) to solve the energy puzzle in the BLR. This heating can be produced in the accretion disc around the massive black hole by the interaction between accreting matter and magnetic field (Kwan et al. 1995; Hirotani et al. 1992). It can also be produced in the atmosphere of the accretion disc by viscous energy release (Blaes et al. 2001). Similarly, Lipari et al. (2005) suggested that Fe II emission could originate in warm regions obscured from the direct ionizing UV photons, the obscuring material being in the form of expanding shells. In particular, they classify IRAS $07598+6508$ as a BAL IR AGN associated with strong early starburst activity. The giant explosive events occuring from the evolution of very massive star would produce shock-heated material.

In view of the huge Fe II emission observed in IRAS $07598+6508$ and of the weakness of all other lines, except Ti II and CrII which actually have similar ionization potential, our aim is to find a region which would emit Fe II lines and no others (or, at least, which would emit very weak HI, $\mathrm{He}$ I, $\mathrm{NaI}, \mathrm{Ca}$ II and $\mathrm{Mg}$ II). It is known since the works of
House (1964) and Jordan (1969) that, in a collisional medium where the radiation field is negligible, each ion is emitted at a specific temperature and therefore in a specific region. The relative importance of these regions strongly depends on the distribution of temperature, and therefore, on the column density of the cloud (as the imposed parameter here is the total heating).

The results obtained with such models are displayed in the last two columns of Table 5, where $H$ is the assumed mechanical heating in erg s $\mathrm{s}^{-1}$. As very weak emission from the Balmer lines is expected, the line ratios have to be considered relative to the Fe II intensity rather than to $\mathrm{H} \beta$ as previously. We used the Fe II $\lambda 4570$ blend as a reference, and its predicted intensity is scaled to the observed one averaged over the four available spectra $\left(\sim 1.7 \times 10^{-13} \mathrm{erg} \mathrm{s}^{-1} \mathrm{~cm}^{-2}\right)$. From this scaling, we determine the emission surface, i.e. the covering factor $f$ of the emission region (given in Table 5, assuming a radius of the BLR of a few times $10^{17} \mathrm{~cm}$ ). The covering factor is determined by comparison between the luminosity in the Fe II $\lambda 4570$ blend and that computed by CLOUDY, assuming a radius for the BLR in agreement with the Kaspi relation (Kaspi et al. 2000). The computed luminosity of Fe II is also a function of the mechanical heating, which is arbitrarily chosen so that the input energy is not larger 


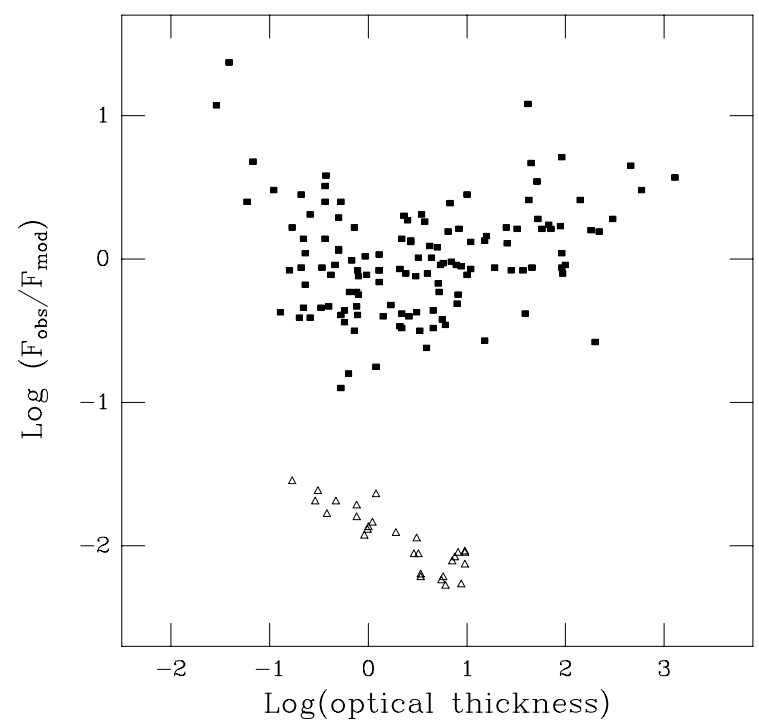

Fig. 4. This figure shows the ratios between the observed and predicted line intensities vs. the optical thicknesses (filled sqares). Also shown are the unobserved lines predicted to have a strong intensity in the model (open triangles).

than the bolometric luminosity. This input energy is mainly determined by the line ratios.

A relatively good fit was obtained for a high density $(n=$ $\left.10^{15} \mathrm{~cm}^{-3}\right)$, high column density $\left(N_{\mathrm{H}}=10^{24} \mathrm{~cm}^{-2}\right)$ model (model 4). The density increase has the advantage of decreasing the relative intensity of $\mathrm{Na}$ I, Ca II, Mg II and Fe II UV with respect to Fe II 24570 . A further increase of the column density would decrease even more $\mathrm{Na}$ I, $\mathrm{Ca}$ II, Mg II but it would increase Fe II UV. The Fe II UV feature at $2355 \AA$ is one of the features that dominate the computed spectra over much of the parameter space in the models discussed by Baldwin et al. (2004). In that paper the authors call for microturbulence to improve the situation. Even in the context of a non-photoionized model, microturbulence can transfer, through line and continuum fluorescence, a fraction of the near UV emission into the optical range, improving the agreement with observed line ratios. A small improvement is actually obtained assuming a microturbulence $v_{\text {turb }}=100 \mathrm{~km} \mathrm{~s}^{-1}$. In particular, the pumping of the Fe II UV lines allows increasing the column density up to $N_{\mathrm{H}}=10^{25} \mathrm{~cm}^{-2}$, inducing a small decrease of $\mathrm{Mg} \mathrm{II}, \mathrm{Ca} \mathrm{II} \mathrm{H}$ and Ca II K (model 5). In this model the temperature is $\leq 7000 \mathrm{~K}$.

The Fe II line ratios show some disagreements: the predicted Fe II $\lambda 3590$ and $\lambda 3910$ are much too strong, and Fe II $\lambda 4975$ is much too weak.

The Fe II $\lambda 4975$ band mainly includes two lines of multiplet 42. It appears that the atomic data base of CLOUDY has no collisional strength listed for these two lines, and so, consequently, a very small one is used in the computations. Not only in IRAS $07598+6508$ are these lines observed with a large intensity, but also in most Fe II emitters, suggesting that their collisional strength is probably not negligible. The underestimation of the collisional strengths may be the explaination for the discrepancy.

The high intensity of the two features, Fe II $\lambda 3590$ and Fe II 23910 , is due to the intercombination multiplets $3,4,10$, 14, 22 and 23, which are all predicted to be strong in the models, but are conspicuously absent in the observed spectra. Whatever the physical parameters assumed for the BLR, these two features are at least as strong as half the value for Fe II $\lambda 4570$.
Figure 4 shows the ratios between the observed and the predicted Fe II line intensities vs. the optical thicknesses. Fe II lines which are strong in the models but could not be detected are shown as upper limits (open triangles). To produce this figure we use the potentiality given by CLOUDY for obtaining the intensity of each Fe II line separately. We have no obvious answer for this problem. We note that it concerns only lines with a moderate transition probability and therefore a moderate optical thickness, but not all lines with such characteristics, and, in particular, not the lines in the red. Indeed the puzzling lines decay from levels around $5 \mathrm{eV}$ down to very low levels (below $2.5 \mathrm{eV}$ ).

Two possible explanations can be invoked: again the lack of collisional strengths between some of these low levels, and the escape probability approximation used in CLOUDY. Avrett \& Loeser (1987) have shown that using the escape probability approximation in multilevel problems instead of solving the transfer equations can induce large errors for all line transitions and, in particular, for the weak ones (see also Collin-Souffrin \& Dumont 1986).

\subsection{The Fel emission spectrum}

Bergeron \& Kunth (1980) suggested the presence of Fe I emission in the spectrum of PHL 1092. Three individual features at $\lambda 3575,3763$ and 3851 were the clearest indications for the presence of this ion. The best identified multiplets were 4, 5, 6, 20,21, 23, 24 and 45. All the lines that are strong in the laboratory were present. All the identified multiplets arise from upper levels at less than $4.8 \mathrm{eV}$.

Kwan et al. (1995) have identified Fe I and Ti II lines, in addition to Fe II, in the spectrum IRAS $07598+6508$. They have noted three regions in the spectral range 3050-4570 $\AA$ whose features cannot be accounted for by Fe II lines. The first region is from 3315 to $3450 \AA$ (outside our observed range), the second from 3520 to $4090 \AA$, the third from 4400 to $4480 \AA$. Kwan et al. suggested that the emission in these three spectral intervals is mainly due to Fe I lines.

Sigut et al. (2004) have predicted the Fe I emission in the BLR in various models. The strongest transitions are decays from low-lying odd parity levels between $\sim 3.5$ to $4.5 \mathrm{eV}$ to the three lowest even parity states, the $a^{5} \mathrm{D}^{\mathrm{e}}$ ground state, $\mathrm{a}^{5} \mathrm{~F}^{\mathrm{e}}$ and $\mathrm{a}^{3} \mathrm{~F}^{\mathrm{e}}$. The strongest predicted multiplet is $23, \mathrm{z}^{5} \mathrm{G}^{\mathrm{o}}-\mathrm{a}^{5} \mathrm{~F}^{\mathrm{e}}$, giving lines near $\lambda 3600 \AA$. The models computed have $N_{\mathrm{e}}=$ $10^{9.6}$ and $10^{10.6} \mathrm{~cm}^{-3}$, and a column density $N_{\mathrm{H}}=10^{23} \mathrm{~cm}^{-2}$. The strongest predicted Fe I lines occur for the highest value of the electron density. However the predicted fraction of Fe I in all computed models is very small $\left(<10^{-3}\right)$ : at large optical depth, $\mathrm{Fe}^{+}$is always the dominant iron species.

Very few Fe I lines are computed by CLOUDY. Their strength is always much lower than that of the Fe II lines $\left(\sim 10^{-2}\right)$, except for the hybrid model (radiative plus mechanical heating) of high density (cf. model 3, Col. 9 of Table 5), where the temperature is less than $6000 \mathrm{~K}$; but we have seen that this model otherwise produces inconsistent results.

The flux of the FeI lines identified by Bergeron \& Kunth (1980) and Kwan et al. (1995) in the spectrum of PHL 1092 and IRAS $07598+6508$ relative to the nearby Fe II flux between 3600 and $3800 \AA$ is much larger than predicted by these models. As we have seen above, we were able to get a good fit by using instead of Fe I lines, Ti II and Cr II lines from multiplets observed in the spectrum of XX Oph. 


\subsection{Comparison of the emission line regions in $I Z w 1$ and IRAS $07598+6508$}

\subsubsection{The broad line region}

In a recent paper (Véron-Cetty et al. 2004), we made a detailed analysis of the emission spectrum of the NLS1 IZw 1. We shall stress here the similarities and differences between the spectra of IZw 1 and IRAS $07598+6508$.

One of the main differences between these two objects is the much larger strength of the metallic lines with respect to the Balmer lines in IRAS $07598+6508$. The parameter $R_{4570}$ (i.e. the ratio of the line flux in the BLR in the range 4430-4685 $\AA$ to the $\mathrm{H} \beta$ flux from the same region) is $\sim 8$ in IRAS $07598+6508$, as compared to 1.7 in IZw 1 . Moreover, the relative Fe II line intensities are significantly different in the two objects. For instance, the intercombination multiplets 16, 25, 26, 29, 35 and 36 are absent or weak in IZw 1 , while they are relatively strong in IRAS $07598+6508$. The $\mathrm{NaID}$ lines are five times stronger relative to $\mathrm{H} \beta$ in IRAS $07598+6508$ than in IZw 1, i.e. their intensities relative to the Fe II lines are the same in the two objects. We had not detected the $\mathrm{Ca}$ II $\mathrm{H}$ and $\mathrm{K}$ lines in IZw 1 . $\mathrm{He}$ I and Si II lines were observed in I Zw 1; they are absent from IRAS $07598+6508$.

In IZw 1 we tentatively identified 27 lines with highexcitation Fe II lines. We had then not yet recognized the importance of Ti II and Cr II. Today we would probably identify many of them with lines from these two ions and so the two metallic spectra are qualitatively but not quantitatively similar.

Although the differences in Fe II line intensities are substantial, the excitation mechanism is probably the same. Indeed we had shown that a standard photoionization model was not able to account for the Fe II strength observed in the BLR of IZw 1 (Véron-Cetty et al. 2004). Difficulties similar to the ones we encounter here occur, such as huge predicted $\operatorname{Ly} \alpha, \operatorname{Mg} I I$, Balmer continuum as well as He I lines in excess of the observations. If again, we adopt mechanical heating alone for the excitation, very good agreement with the observations is obtained (except for Fe II 23910) with a density $n=10^{14} \mathrm{~cm}^{-3}$, a column density $N_{\mathrm{H}}=10^{24} \mathrm{~cm}^{-2}$ and a heating $H=2 \times 10^{44} \mathrm{erg} \mathrm{s}^{-1}$. To account for the observed luminosities a covering factor $f=5 \%$ is necessary. These characteristics of the emission region are very close to that obtained for IRAS $07598+6508$, although the higher intensity of $\mathrm{Fe}$ II relative to $\mathrm{H} \beta$ in the latter object, together with the increase of the relative intensities of some intercombination mutiplets, imply a somewhat higher density and column density $\left(n=10^{15} \mathrm{~cm}^{-3}\right.$ and $\left.N_{\mathrm{H}}=10^{25} \mathrm{~cm}^{-2}\right)$.

\subsubsection{The narrow line regions}

In the spectrum of IZw 1 we had found a very rich low excitation NLR together with two high excitation NLR. Nothing similar was found in IRAS $07598+6508$.

\section{Conclusion}

We have shown that the emission line spectrum of the NLS1 Seyfert galaxy IRAS $07598+6508$ is dominated by a BLR region emitting mainly, apart from the Balmer lines, Fe II, Ti II and Cr II lines. The best model accounting for this BLR is a purely collisional model with a high density $\left(n=10^{15} \mathrm{~cm}^{-3}\right)$, a high column density $\left(N_{\mathrm{H}}=10^{24} \mathrm{~cm}^{-2}\right)$, a microturbulence of $100 \mathrm{~km} \mathrm{~s}^{-1}$, a mechanical heating of the order of one tenth of the bolometric luminosity $\left(\sim 10^{45} \mathrm{erg} \mathrm{s}^{-1}\right.$ and a low covering factor $(f=5 \%)$. This BLR is qualitatively similar to the one observed in IZw 1 , but we have not found traces in IRAS $07598+6508$ of the narrow line regions found in the latter object.

Acknowledgements. We gratefully thank Gary Schmidt, who kindly put at our disposal his spectrum of IRAS $07598+6508$, and S. Collin for helpful discussions.

\section{References}

Avrett, E. H., \& Loeser, R. 1987, Numerical Radiative Transfer, ed. W. Kalkofen (Cambridge University press), 135

Baldwin, J. A., Ferland, G. J., Korista, K. T., Hamann, F., \& LaCluyzé, A. 2004, ApJ, 615, 610

Bergeron, J., \& Kunth, D. 1980, A\&A, 85, L11

Blaes, O., Hubeny, I., Agol, E., \& Krolik, J. H. 2001, ApJ, 563, 560

Boroson, T. A., \& Meyers, K. A. 1992, ApJ, 397, 442

Boyce, P. J., Disney, M. J., Blades, J. C., et al. 1996, ApJ, 473, 760

Brotherton, M. S., Wills, B. J., Francis, P. J., \& Steidel, C. C. 1994, ApJ, 430, 495

Canalizo, G., \& Stockton, A. 2000, AJ, 120, 1750

Collin-Souffrin, S. 1986, A\&A, 166, 115

Collin-Souffrin, S. \& Dumont, S. 1986, A\&A, 166, 13

Collin-Souffrin, S., Dumont, S., \& Tully, M. 1982, A\&A, 106, 362

Cool, R. J., Howell, S. B., Pena, M., Adamson, A. J., \& Thompson, R. R. 2005, PASP, 117, 462

de Grijp, M. H. K., Miley, G. K., \& Lub, J. 1987, A\&AS, 70, 95

Ferland, G. J. 2002, Hazy, a brief introduction to cloudy, University of Kentucky, Department of physics and astronomy, Internal report

Gallagher, S. C., Brandt, W. N., Sambruna, R. M., Mathur, S., \& Yamasaki, N. 1999, ApJ, 519,549

Green, P. J., Aldcroft, T. L., Mathur, S., Wilkes, B. J., \& Elvis, M. 2001, ApJ, 558, 109 Hines, D. C., \& Wills, B. J. 1995, ApJ, 448, L69

Hirotani, K., Takahashi, M., Nitta, S., \& Tomimatsu, A. 1992, ApJ, 386, 455 House, L. L. 1964, ApJS, 8, 307

Imanishi, M., \& Terashima, Y. 2004, AJ, 127, 758

Jordan, C. 1969, MNRAS, 142, 501

Kaspi, S., Smith, P. S., Netzer, H., et al. 2000, ApJ, 533, 631

Kim, D.-C., Veilleux, S., \& Sanders, D. B. 2002, ApJS, 143, 277

Kwan, J., Cheng, F.-Z., Fang, L.-Z., Zheng, W., \& Ge, J. 1995, ApJ, 440, 628

Lanzetta, K. M., Turnshek, D. A., \& Sandoval, J. 1993, ApJS, 84, 109

Lawrence, A., Saunders, A., Rowan-Robinson, M., et al. 1988, MNRAS, 235, 261

Lawrence, A., Elvis, M., Wilkes, B. J., McHardy, I., \& Brandt, N. 1997, MNRAS, 285, 879 Lipari, S. 1994, ApJ, 436, 102

Lipari, S., Terlevich, R., \& Macchetto, F. 1993, ApJ, 406, 451

Lipari, S., Terlevich, R., Zheng, W., et al. 2005, MNRAS, 360, 416

Low, F. J., Huchra, J. P., Kleinmann, S. G., \& Cutri, R. M. 1988, ApJ, 327, L41

Low, F. J., Cutri, R. M., Kleinmann, S. G., \& Huchra, J. P. 1989, ApJ, 340, L1

Marziani, P., Sulentic, J. W., Zamanov, R., et al. 2003, ApJS, 145, 199

Merrill, P. W. 1924, PASP, 36, 225

Merrill, P. W. 1951, ApJ, 114, 37

Merrill, P. W. 1961, ApJ, 133, 503

Nagar, N. M., Wilson, A. S., Falcke, H., Veilleux, S., \& Maiolino, R. 2003, A\&A, 409, 115 Ogle, P. M., Cohen, M. H., Miller, J. S., et al. 1999, ApJS, 125, 1

Oke, J. B., Cohen, J. G., Carr, M., et al. 1995, PASP, 107, 375

Rupke, D. S., Veilleux, S., \& Sanders, D. B. 2005, ApJ, 632, 751

Sanders, D. B., Soifer, B. T., Elias, J. H., Neugebauer, G., \& Matthews, K. 1988, ApJ, 328, L35

Schmidt, G. D., \& Hines, D. C. 1999, ApJ, 512, 125

Schmidt, G. D., Stockman, H. S., \& Smith, P. S. 1992, ApJ, 398, L57

Scoville, N. Z., Evans, A. S., Thompson, R., et al. 2000, AJ, 119, 991

Sigut, T. A. A., Pradhan, A. N., \& Nahar, S. N. 2004, ApJ, 611, 81

Surace, J. A., \& Sanders, D. B. 2000, AJ, 120, 604

Taniguchi, Y., Kawara, K., Murayama, T., \& Sato, Y. 1994, AJ, 107, 1668

Turnshek, D. A., Monier, E. M., Sirola, C. J., \& Espey, B. R. 1997, ApJ, 476, 40

Véron, P., Lindblad, P. O., Zuiderwijk, E. J., Véron-Cetty, M.-P., \& Adams, G. 1980, A\&A, 87,245

Véron-Cetty, M.-P., Véron, \& Goncalves, A. C. 2001, A\&A, 372, 730

Véron-Cetty, M.-P., Joly, M., \& Véron 2004, A\&A, 417, 515

Vestergaard, M., \& Wilkes, B. J. 2001, ApJS, 134, 1

Zheng, X. Z., Xia, X. Y., Mao, S., Wu, H., \& Deng, Z. G. 2002, AJ, 124, 18 


\section{Online Material}




\section{Appendix A}

Table A.1. Observed line ratios (relative to $\mathrm{H} \beta$ ) in the IRAS $07598+6508$ BLR. The H $\beta$ flux is $\sim 2.3 \times 10^{-14} \mathrm{erg} \mathrm{s}^{-1} \mathrm{~cm}^{-2}$. An " $\mathrm{n}$ " indicates that the line has not been detected, an "h" that it is outside the spectral range or in a region of the spectrum masked because of the presence of poorly corrected atmospheric features.

\begin{tabular}{|c|c|c|c|c|c|}
\hline Line & $\lambda(\AA)$ & KPNO 4-m & 2.3-m Bok & Keck & KPNO 2.1-m \\
\hline$\overline{\mathrm{H} \beta}$ & 4861.30 & 1.00 & 1.00 & 1.00 & 1.00 \\
\hline $\mathrm{H} \alpha$ & 6562.80 & 6.71 & 8.18 & 5.87 & 4.28 \\
\hline $\mathrm{H} \gamma$ & 4340.40 & $\mathrm{~h}$ & 0.21 & 0.29 & 0.28 \\
\hline $\mathrm{H} \delta$ & 4101.74 & $\mathrm{~h}$ & 0.08 & 0.15 & 0.07 \\
\hline Ti II 6 & 3444.31 & $\mathrm{~h}$ & $\mathrm{~h}$ & $\mathrm{~h}$ & 0.32 \\
\hline Ti II 6 & 3461.50 & $\mathrm{~h}$ & $\mathrm{~h}$ & 0.15 & 0.12 \\
\hline Ti II 99 & 3465.56 & $\mathrm{~h}$ & $\mathrm{~h}$ & 0.15 & 0.12 \\
\hline Fe II 114 & 3468.68 & $\mathrm{~h}$ & $\mathrm{~h}$ & 0.30 & 0.25 \\
\hline Fe II 114 & 3493.47 & $\mathrm{~h}$ & $\mathrm{~h}$ & 0.28 & 0.18 \\
\hline $\mathrm{Fe} \mathrm{II]} 16$ & 3494.67 & $\mathrm{~h}$ & $\mathrm{~h}$ & 0.56 & 0.36 \\
\hline Fe II] 16 & 3507.40 & $\mathrm{~h}$ & $\mathrm{~h}$ & 0.15 & $\mathrm{n}$ \\
\hline Cr II] 2 & 3511.84 & $\mathrm{~h}$ & $\mathrm{~h}$ & 0.48 & 0.45 \\
\hline Ti II] 15 & 3552.85 & $\mathrm{~h}$ & $\mathrm{~h}$ & 0.02 & 0.06 \\
\hline Ti II] 15 & 3561.57 & $\mathrm{~h}$ & $\mathrm{~h}$ & 0.25 & 0.14 \\
\hline Ti II] 15 & 3573.74 & $\mathrm{~h}$ & $\mathrm{~h}$ & 0.55 & 0.46 \\
\hline Ti II] 15 & 3587.13 & $\mathrm{~h}$ & $\mathrm{~h}$ & 0.46 & 0.15 \\
\hline Ti II] 15 & 3596.05 & h & $\mathrm{h}$ & 0.11 & 0.07 \\
\hline Ti II] 76 & 3596.55 & $\mathrm{~h}$ & $\mathrm{~h}$ & 0.11 & 0.07 \\
\hline Ti II] 76 & 3608.89 & $\mathrm{~h}$ & $\mathrm{~h}$ & 0.33 & 0.16 \\
\hline Ti II] 76 & 3613.30 & $\mathrm{~h}$ & $\mathrm{~h}$ & 0.33 & 0.16 \\
\hline Ti II 52 & 3624.83 & $\mathrm{~h}$ & $\mathrm{~h}$ & 0.39 & 0.51 \\
\hline Cr II 12 & 3631.49 & $\mathrm{~h}$ & $\mathrm{~h}$ & 0.14 & $\mathrm{n}$ \\
\hline Cr II 12 & 3631.72 & $\mathrm{~h}$ & $\mathrm{~h}$ & 0.14 & $\mathrm{n}$ \\
\hline Cr II] 1 & 3651.68 & $\mathrm{~h}$ & $\mathrm{~h}$ & 0.21 & 0.06 \\
\hline Ti II 75 & 3659.76 & $\mathrm{~h}$ & $\mathrm{~h}$ & 0.00 & $\mathrm{n}$ \\
\hline Ti II 75 & 3662.24 & $\mathrm{~h}$ & $\mathrm{~h}$ & 0.04 & $\mathrm{n}$ \\
\hline Cr II 12 & 3677.69 & $\mathrm{~h}$ & $\mathrm{~h}$ & 0.06 & 0.06 \\
\hline Cr II 12 & 3677.86 & $\mathrm{~h}$ & $\mathrm{~h}$ & 0.06 & 0.06 \\
\hline Cr II 12 & 3677.93 & $\mathrm{~h}$ & $\mathrm{~h}$ & 0.06 & 0.06 \\
\hline Ti II 14 & 3685.19 & $\mathrm{~h}$ & $\mathrm{~h}$ & 0.15 & $\mathrm{n}$ \\
\hline Cr II 12 & 3712.97 & h & $\mathrm{h}$ & 0.14 & 0.08 \\
\hline Cr II 12 & 3713.04 & $\mathrm{~h}$ & $\mathrm{~h}$ & 0.07 & 0.04 \\
\hline Cr II 20 & 3715.19 & $\mathrm{~h}$ & $\mathrm{~h}$ & 0.08 & 0.05 \\
\hline Cr II] 117 & 3727.37 & $\mathrm{~h}$ & $\mathrm{~h}$ & 0.12 & 0.20 \\
\hline Cr II] 117 & 3737.55 & $\mathrm{~h}$ & $\mathrm{~h}$ & 0.03 & 0.05 \\
\hline Ti II 72 & 3741.63 & $\mathrm{~h}$ & $\mathrm{~h}$ & 0.22 & 0.20 \\
\hline Ti II 72 & 3757.68 & $\mathrm{~h}$ & $\mathrm{~h}$ & 0.07 & 0.05 \\
\hline Ti II 13 & 3759.29 & $\mathrm{~h}$ & $\mathrm{~h}$ & 0.15 & 0.10 \\
\hline Ti II 13 & 3761.32 & $\mathrm{~h}$ & $\mathrm{~h}$ & 0.15 & 0.10 \\
\hline $\mathrm{Fe}$ II] 29 & 3764.09 & $\mathrm{~h}$ & $\mathrm{~h}$ & 0.29 & 0.56 \\
\hline Ti II] 12 & 3813.39 & $\mathrm{~h}$ & $\mathrm{~h}$ & 0.03 & 0.05 \\
\hline Ti II] 12 & 3814.38 & $\mathrm{~h}$ & $\mathrm{~h}$ & 0.03 & 0.05 \\
\hline Fe II] 29 & 3824.91 & $\mathrm{~h}$ & $\mathrm{~h}$ & 0.30 & 0.21 \\
\hline $\mathrm{Fe}$ II] 23 & 3833.02 & $\mathrm{~h}$ & $\mathrm{~h}$ & 0.05 & 0.03 \\
\hline Mg II 5 & 3848.24 & $\mathrm{~h}$ & $\mathrm{~h}$ & 0.29 & 0.26 \\
\hline Mg II 5 & 3850.40 & $\mathrm{~h}$ & $\mathrm{~h}$ & 0.29 & 0.26 \\
\hline Fe II] 29 & 3872.77 & $\mathrm{~h}$ & $\mathrm{~h}$ & 0.16 & 0.17 \\
\hline Ti II 34 & 3900.55 & $\mathrm{~h}$ & $\mathrm{~h}$ & 0.05 & $\mathrm{n}$ \\
\hline Fe II] 29 & 3908.54 & $\mathrm{~h}$ & $\mathrm{~h}$ & 0.28 & 0.41 \\
\hline Ca II K & 3933.66 & $\mathrm{~h}$ & $\mathrm{~h}$ & 0.22 & 0.28 \\
\hline Fe II] 3 & 3938.29 & $\mathrm{~h}$ & $\mathrm{~h}$ & 0.25 & 0.40 \\
\hline Fe II] 29 & 3964.57 & $\mathrm{~h}$ & 0.04 & 0.06 & 0.09 \\
\hline $\mathrm{Ca}$ II H & 3968.47 & $\mathrm{~h}$ & 0.14 & 0.19 & 0.29 \\
\hline Fe II] 29 & 3974.16 & $\mathrm{~h}$ & $\mathrm{n}$ & 0.11 & 0.08 \\
\hline Fe II] 29 & 4002.07 & $\mathrm{~h}$ & $\mathrm{n}$ & 0.04 & 0.15 \\
\hline Ti II] 11 & 4012.37 & $\mathrm{~h}$ & 0.16 & 0.14 & 0.11 \\
\hline Ti II] 11 & 4025.14 & $\mathrm{~h}$ & 0.09 & 0.14 & 0.18 \\
\hline Ti II 87 & 4028.33 & $\mathrm{~h}$ & 0.05 & 0.07 & 0.09 \\
\hline Cr II] 19 & 4051.97 & $\mathrm{~h}$ & 0.01 & 0.04 & 0.03 \\
\hline Ti II 87 & 4053.81 & $\mathrm{~h}$ & 0.01 & 0.04 & 0.03 \\
\hline
\end{tabular}


M.-P. Véron-Cetty et al.: IRAS 07598+6508, Online Material p 3

Table A.1. continued.

\begin{tabular}{|c|c|c|c|c|c|}
\hline Line & $\lambda(\AA)$ & KPNO 4-m & 2.3-m Bok & Keck & KPNO 2.1-m \\
\hline Cr II] 19 & 4054.11 & $\mathrm{~h}$ & 0.01 & 0.04 & 0.03 \\
\hline Ti II 11 & 4056.21 & $\mathrm{~h}$ & 0.01 & 0.04 & 0.03 \\
\hline Cr II 19 & 4063.94 & $\mathrm{~h}$ & 0.22 & 0.13 & 0.36 \\
\hline Fe II] 21 & 4075.95 & $\mathrm{~h}$ & 0.11 & 0.19 & 0.10 \\
\hline Fe II 28 & 4087.27 & $\mathrm{~h}$ & 0.03 & 0.03 & 0.03 \\
\hline $\mathrm{Fe} I \mathrm{II}] 21$ & 4119.52 & $\mathrm{~h}$ & 0.07 & 0.08 & 0.07 \\
\hline Fe II 28 & 4122.64 & $\mathrm{~h}$ & 0.11 & 0.13 & 0.12 \\
\hline Fe II 27 & 4128.73 & $\mathrm{~h}$ & 0.19 & 0.32 & 0.24 \\
\hline Fe II] 12 & 4151.79 & $\mathrm{~h}$ & 0.07 & 0.14 & $\mathrm{n}$ \\
\hline Ti II 21 & 4161.52 & $\mathrm{~h}$ & 0.08 & 0.04 & 0.08 \\
\hline Ti II 105 & 4163.64 & $\mathrm{~h}$ & 0.08 & 0.04 & 0.08 \\
\hline Ti II 105 & 4171.90 & $\mathrm{~h}$ & 0.02 & 0.02 & 0.02 \\
\hline Fe II 27 & 4173.45 & $\mathrm{~h}$ & 0.16 & 0.21 & 0.23 \\
\hline Ti II 105 & 4174.09 & $\mathrm{~h}$ & 0.05 & 0.06 & 0.07 \\
\hline Fe II] 21 & 4177.69 & $\mathrm{~h}$ & 0.21 & 0.28 & 0.30 \\
\hline Fe II 28 & 4178.86 & $\mathrm{~h}$ & 0.20 & 0.26 & 0.28 \\
\hline Ti II 21 & 4184.33 & $\mathrm{~h}$ & 0.09 & 0.06 & $\mathrm{n}$ \\
\hline Ti II 21 & 4190.29 & $\mathrm{~h}$ & 0.03 & 0.02 & $\mathrm{n}$ \\
\hline Cr II 26 & 4207.35 & $\mathrm{~h}$ & 0.27 & 0.28 & 0.28 \\
\hline Fe II 27 & 4233.17 & $\mathrm{~h}$ & 0.69 & 0.68 & 0.78 \\
\hline Cr II 31 & 4242.38 & $\mathrm{~h}$ & 0.32 & 0.43 & 0.46 \\
\hline Fe II 28 & 4258.16 & $\mathrm{~h}$ & 0.18 & 0.15 & 0.18 \\
\hline Fe II] 21 & 4258.34 & $\mathrm{~h}$ & 0.09 & 0.08 & 0.09 \\
\hline Cr II 31 & 4261.90 & $\mathrm{~h}$ & 0.09 & 0.08 & 0.09 \\
\hline Fe II 27 & 4273.32 & $\mathrm{~h}$ & 0.15 & 0.17 & 0.25 \\
\hline Cr II 31 & 4275.54 & $\mathrm{~h}$ & 0.08 & 0.08 & 0.12 \\
\hline $\mathrm{Fe}$ II 32 & 4278.16 & $\mathrm{~h}$ & 0.15 & 0.17 & 0.25 \\
\hline Cr II 31 & 4284.20 & $\mathrm{~h}$ & 0.04 & 0.04 & 0.05 \\
\hline Ti II 20 & 4287.89 & $\mathrm{~h}$ & 0.08 & 0.08 & 0.10 \\
\hline Ti II 41 & 4290.22 & $\mathrm{~h}$ & 0.12 & 0.12 & 0.15 \\
\hline Ti II 20 & 4294.10 & $\mathrm{~h}$ & 0.08 & 0.08 & 0.10 \\
\hline Fe II 28 & 4296.57 & $\mathrm{~h}$ & 0.28 & 0.28 & 0.35 \\
\hline Ti II 41 & 4300.05 & $\mathrm{~h}$ & 0.08 & 0.08 & 0.10 \\
\hline Ti II 41 & 4301.93 & $\mathrm{~h}$ & 0.06 & 0.06 & 0.07 \\
\hline Fe II 27 & 4303.17 & $\mathrm{~h}$ & 0.20 & 0.20 & 0.25 \\
\hline Ti II 41 & 4307.90 & $\mathrm{~h}$ & 0.08 & 0.08 & 0.10 \\
\hline Ti II 41 & 4312.86 & $\mathrm{~h}$ & 0.13 & 0.15 & 0.19 \\
\hline Fe II 32 & 4314.29 & $\mathrm{~h}$ & 0.27 & 0.29 & 0.38 \\
\hline Ti II 41 & 4314.98 & $\mathrm{~h}$ & 0.07 & 0.07 & 0.09 \\
\hline Ti II 94 & 4316.81 & $\mathrm{~h}$ & 0.05 & 0.06 & 0.08 \\
\hline Ti II 94 & 4330.26 & $\mathrm{~h}$ & 0.15 & 0.12 & 0.12 \\
\hline Ti II 41 & 4330.71 & $\mathrm{~h}$ & 0.29 & 0.24 & 0.23 \\
\hline Ti II 20 & 4337.92 & $\mathrm{~h}$ & 0.09 & 0.07 & 0.07 \\
\hline Fe II 32 & 4338.70 & $\mathrm{~h}$ & 0.15 & 0.12 & 0.12 \\
\hline Ti II 20 & 4344.29 & $\mathrm{~h}$ & 0.09 & 0.07 & 0.07 \\
\hline Ti II 94 & 4350.83 & $\mathrm{~h}$ & 0.06 & 0.05 & 0.09 \\
\hline Fe II 27 & 4351.76 & $\mathrm{~h}$ & 0.38 & 0.34 & 0.63 \\
\hline Fe II 148 & 4360.03 & $\mathrm{~h}$ & 0.54 & 0.63 & 0.51 \\
\hline Ti II 104 & 4367.66 & $\mathrm{~h}$ & 0.05 & 0.02 & 0.04 \\
\hline Fe II 28 & 4369.40 & $\mathrm{~h}$ & 0.10 & 0.05 & 0.09 \\
\hline Fe II 33 & 4372.22 & $\mathrm{~h}$ & 0.06 & 0.03 & 0.05 \\
\hline Ti II 93 & 4374.82 & $\mathrm{~h}$ & 0.02 & 0.01 & 0.02 \\
\hline Fe II 32 & 4384.32 & $\mathrm{~h}$ & 0.34 & 0.37 & 0.51 \\
\hline Fe II 27 & 4385.38 & $\mathrm{~h}$ & 0.20 & 0.22 & 0.31 \\
\hline Ti II 104 & 4386.80 & $\mathrm{~h}$ & 0.07 & 0.07 & 0.10 \\
\hline Ti II 61 & 4390.98 & $\mathrm{~h}$ & 0.05 & 0.04 & 0.05 \\
\hline Ti II] 51 & 4394.07 & $\mathrm{~h}$ & 0.08 & 0.07 & 0.08 \\
\hline
\end{tabular}


M.-P. Véron-Cetty et al.: IRAS 07598+6508, Online Material p 4

Table A.1. continued.

\begin{tabular}{|c|c|c|c|c|c|}
\hline Line & $\lambda(\AA)$ & KPNO 4-m & 2.3-m Bok & Keck & KPNO 2.1-m \\
\hline Ti II 19 & 4395.03 & $\mathrm{~h}$ & 0.08 & 0.07 & 0.08 \\
\hline Ti II 61 & 4395.85 & $\mathrm{~h}$ & 0.08 & 0.07 & 0.08 \\
\hline Ti II 61 & 4398.31 & $\mathrm{~h}$ & 0.02 & 0.02 & 0.02 \\
\hline Ti II] 51 & 4399.79 & $\mathrm{~h}$ & 0.16 & 0.15 & 0.16 \\
\hline Ti II 61 & 4409.22 & $\mathrm{~h}$ & 0.03 & 0.03 & 0.04 \\
\hline Ti II 61 & 4409.48 & $\mathrm{~h}$ & 0.03 & 0.03 & 0.04 \\
\hline Ti II 115 & 4411.08 & $\mathrm{~h}$ & 0.06 & 0.07 & 0.09 \\
\hline Fe II 32 & 4413.60 & h & 0.16 & 0.16 & 0.21 \\
\hline Fe II 27 & 4416.82 & $\mathrm{~h}$ & 0.32 & 0.33 & 0.43 \\
\hline Ti II] 40 & 4417.72 & $\mathrm{~h}$ & 0.10 & 0.10 & 0.13 \\
\hline Ti II] 51 & 4418.34 & $\mathrm{~h}$ & 0.16 & 0.16 & 0.21 \\
\hline Ti II 93 & 4421.95 & $\mathrm{~h}$ & 0.10 & 0.10 & 0.13 \\
\hline Ti II] 40 & 4441.73 & $\mathrm{~h}$ & 0.16 & 0.10 & 0.03 \\
\hline Ti II 19 & 4443.80 & $\mathrm{~h}$ & 0.22 & 0.15 & 0.04 \\
\hline Ti II 31 & 4444.50 & $\mathrm{~h}$ & 0.11 & 0.07 & 0.02 \\
\hline Ti II 19 & 4450.48 & $\mathrm{~h}$ & 0.28 & 0.52 & 0.93 \\
\hline Fe II] 26 & 4461.43 & $\mathrm{~h}$ & 0.07 & 0.04 & 0.03 \\
\hline Ti II] 40 & 4464.45 & $\mathrm{~h}$ & 0.07 & 0.04 & 0.03 \\
\hline Ti II 31 & 4468.49 & $\mathrm{~h}$ & 0.24 & 0.14 & 0.11 \\
\hline Ti II 18 & 4469.13 & $\mathrm{~h}$ & 0.07 & 0.04 & 0.03 \\
\hline Ti II] 40 & 4470.86 & $\mathrm{~h}$ & 0.07 & 0.04 & 0.03 \\
\hline Fe II 37 & 4472.92 & $\mathrm{~h}$ & 0.36 & 0.61 & 0.59 \\
\hline Ti II 115 & 4488.32 & $\mathrm{~h}$ & 0.07 & 0.06 & 0.10 \\
\hline Fe II 37 & 4489.18 & $\mathrm{~h}$ & 0.29 & 0.26 & 0.38 \\
\hline Fe II 37 & 4491.40 & $\mathrm{~h}$ & 0.29 & 0.26 & 0.38 \\
\hline Ti II] 18 & 4493.53 & $\mathrm{~h}$ & 0.07 & 0.06 & 0.10 \\
\hline Ti II 31 & 4501.27 & $\mathrm{~h}$ & 0.48 & 0.29 & 0.22 \\
\hline Fe II 38 & 4508.28 & $\mathrm{~h}$ & 0.30 & 0.35 & 0.42 \\
\hline Fe II 37 & 4515.34 & $\mathrm{~h}$ & 0.39 & 0.46 & 0.55 \\
\hline Fe II 37 & 4520.22 & $\mathrm{~h}$ & 0.46 & 0.54 & 0.65 \\
\hline Fe II 38 & 4522.63 & $\mathrm{~h}$ & 0.30 & 0.35 & 0.42 \\
\hline Ti II 82 & 4529.46 & $\mathrm{~h}$ & 0.11 & 0.09 & 0.02 \\
\hline Ti II 50 & 4533.97 & $\mathrm{~h}$ & 0.23 & 0.17 & 0.03 \\
\hline Fe II 37 & 4534.17 & $\mathrm{~h}$ & 0.23 & 0.17 & 0.03 \\
\hline Fe II 38 & 4541.52 & $\mathrm{~h}$ & 0.37 & 0.42 & 0.62 \\
\hline Fe II 38 & 4549.47 & $\mathrm{~h}$ & 0.30 & 0.34 & 0.49 \\
\hline Cr II 44 & 4555.02 & $\mathrm{~h}$ & 0.15 & 0.15 & 0.14 \\
\hline Fe II 37 & 4555.89 & $\mathrm{~h}$ & 0.58 & 0.61 & 0.54 \\
\hline Cr II 44 & 4558.66 & $\mathrm{~h}$ & 0.29 & 0.31 & 0.27 \\
\hline Ti II 50 & 4563.76 & $\mathrm{~h}$ & 0.15 & 0.15 & 0.14 \\
\hline Ti II 82 & 4571.97 & $\mathrm{~h}$ & 0.18 & 0.16 & 0.17 \\
\hline Fe II 38 & 4576.33 & $\mathrm{~h}$ & 0.33 & 0.29 & 0.31 \\
\hline $\mathrm{Fe} \mathrm{II]} 26$ & 4580.06 & $\mathrm{~h}$ & 0.18 & 0.16 & 0.17 \\
\hline Fe II 37 & 4582.83 & $\mathrm{~h}$ & 0.37 & 0.33 & 0.34 \\
\hline Fe II 38 & 4583.83 & $\mathrm{~h}$ & 0.31 & 0.28 & 0.29 \\
\hline Fe II] 26 & 4584.00 & $\mathrm{~h}$ & 0.07 & 0.07 & 0.07 \\
\hline Cr II 44 & 4588.22 & h & 0.10 & 0.26 & 0.38 \\
\hline Cr II 44 & 4592.09 & $\mathrm{~h}$ & 0.08 & 0.21 & 0.31 \\
\hline Fe II] 43 & 4601.38 & $\mathrm{~h}$ & 0.61 & 0.36 & 0.05 \\
\hline Cr II 44 & 4616.61 & $\mathrm{~h}$ & 0.04 & 0.05 & 0.08 \\
\hline Cr II 44 & 4618.84 & $\mathrm{~h}$ & 0.07 & 0.10 & 0.16 \\
\hline Fe II 38 & 4620.51 & $\mathrm{~h}$ & 0.18 & 0.25 & 0.39 \\
\hline Fe II 37 & 4629.34 & $\mathrm{~h}$ & 1.09 & 1.04 & 1.03 \\
\hline Fe II 38 & 4648.23 & $\mathrm{~h}$ & 0.08 & 0.06 & 0.03 \\
\hline $\mathrm{Fe}$ II] 25 & 4648.94 & $\mathrm{~h}$ & 0.10 & 0.07 & 0.04 \\
\hline $\mathrm{Fe}$ II] 43 & 4656.98 & $\mathrm{~h}$ & 0.14 & 0.11 & 0.06 \\
\hline $\mathrm{Fe}$ II] 44 & 4663.71 & $\mathrm{~h}$ & 0.26 & 0.28 & 0.39 \\
\hline Fe II] 26 & 4665.80 & $\mathrm{~h}$ & 0.04 & 0.04 & 0.06 \\
\hline
\end{tabular}


M.-P. Véron-Cetty et al.: IRAS 07598+6508, Online Material p 5

Table A.1. continued.

\begin{tabular}{|c|c|c|c|c|c|}
\hline Line & $\lambda(\AA)$ & KPNO 4-m & 2.3-m Bok & Keck & KPNO 2.1-m \\
\hline Fe II 37 & 4666.75 & $\mathrm{~h}$ & 0.13 & 0.14 & 0.19 \\
\hline Fe II] 25 & 4670.18 & $\mathrm{~h}$ & 0.05 & 0.06 & 0.08 \\
\hline Fe II] 17 & 4724.07 & $\mathrm{~h}$ & 0.21 & 0.10 & 0.46 \\
\hline Fe II] 31 & 4772.77 & $\mathrm{~h}$ & 0.08 & 0.10 & 0.45 \\
\hline Ti II 17 & 4798.53 & $\mathrm{~h}$ & 0.03 & 0.06 & 0.18 \\
\hline Ti II 92 & 4805.10 & $\mathrm{~h}$ & 0.07 & 0.12 & 0.35 \\
\hline Fe II] 11 & 4818.26 & $\mathrm{~h}$ & 0.35 & 0.30 & 0.61 \\
\hline Cr II 30 & 4836.22 & $\mathrm{~h}$ & 0.35 & 0.53 & 0.89 \\
\hline Cr II 30 & 4848.24 & $\mathrm{~h}$ & 0.25 & 0.17 & 0.30 \\
\hline Fe II] 25 & 4855.55 & $\mathrm{~h}$ & 0.49 & 0.34 & 0.60 \\
\hline Fe II] 25 & 4871.28 & $\mathrm{~h}$ & 0.13 & 0.13 & 0.27 \\
\hline Ti II 114 & 4874.03 & $\mathrm{~h}$ & 0.13 & 0.13 & 0.27 \\
\hline Cr II 30 & 4876.41 & $\mathrm{~h}$ & 0.10 & 0.09 & 0.20 \\
\hline Fe II] 36 & 4893.82 & $\mathrm{~h}$ & 0.47 & 0.49 & 1.01 \\
\hline Ti II 114 & 4911.20 & $\mathrm{~h}$ & 0.04 & 0.06 & 0.18 \\
\hline Fe II 42 & 4923.92 & $\mathrm{~h}$ & 1.00 & 1.02 & 1.72 \\
\hline Fe II] 36 & 4924.92 & $\mathrm{~h}$ & 0.20 & 0.20 & 0.34 \\
\hline Fe II] 36 & 4947.32 & $\mathrm{~h}$ & 0.27 & 0.28 & 0.74 \\
\hline Ti II & 4961.72 & 0.16 & 0.16 & 0.21 & 0.63 \\
\hline $\mathrm{Fe} \mathrm{II]} 25$ & 4991.13 & 0.21 & 0.19 & 0.20 & 0.29 \\
\hline Fe II] 36 & 4993.35 & 0.85 & 0.75 & 0.82 & 1.17 \\
\hline $\mathrm{Fe}$ II] 25 & 5000.73 & 0.09 & 0.08 & 0.08 & 0.12 \\
\hline Fe II 42 & 5018.45 & 1.73 & 1.29 & 1.36 & 1.76 \\
\hline Fe II] 36 & 5036.94 & 0.24 & 0.26 & 0.27 & 1.35 \\
\hline ? & 5050.62 & 0.31 & 0.19 & 0.24 & 0.20 \\
\hline Ti II 113 & 5072.30 & 0.61 & 0.37 & 0.42 & 0.77 \\
\hline $\mathrm{Fe}$ II] 35 & 5100.66 & 0.64 & 0.36 & 0.38 & 0.58 \\
\hline Fe II] 35 & 5120.34 & 0.61 & 0.38 & 0.40 & 0.36 \\
\hline $\mathrm{Fe}$ II] 35 & 5132.67 & 0.29 & 0.20 & 0.24 & 0.18 \\
\hline Fe II] 35 & 5136.80 & 0.14 & 0.10 & 0.12 & 0.09 \\
\hline Fe II] 35 & 5146.13 & 0.34 & 0.24 & 0.29 & 0.22 \\
\hline Fe II] 35 & 5150.94 & 0.21 & 0.15 & 0.18 & 0.14 \\
\hline Fe II] 35 & 5154.40 & 0.17 & 0.12 & 0.15 & 0.11 \\
\hline Fe II] 35 & 5161.18 & 0.33 & 0.19 & $\mathrm{n}$ & 0.53 \\
\hline Fe II 42 & 5169.03 & 1.49 & 1.15 & 1.20 & 0.88 \\
\hline Fe II] 35 & 5171.74 & 0.37 & 0.29 & 0.30 & 0.22 \\
\hline Fe II 49 & 5197.57 & 1.87 & 1.36 & 1.32 & 1.38 \\
\hline Ti II 70 & 5226.53 & 0.40 & 0.44 & 0.41 & 0.33 \\
\hline Fe II 49 & 5234.62 & 1.56 & 0.96 & 0.97 & 1.26 \\
\hline Fe II 49 & 5254.92 & 0.37 & 0.45 & 0.38 & 0.25 \\
\hline Fe II 41 & 5256.89 & 0.13 & 0.16 & 0.13 & 0.09 \\
\hline Fe II 48 & 5264.80 & 0.83 & 0.51 & 0.51 & 0.77 \\
\hline Fe II 49 & 5275.99 & 0.83 & 0.51 & 0.51 & 0.77 \\
\hline Fe II 41 & 5284.09 & 1.00 & 0.97 & 0.85 & 0.54 \\
\hline Fe II 49 & 5316.61 & 0.59 & 0.45 & 0.41 & 0.45 \\
\hline Fe II 48 & 5316.78 & 1.48 & 1.13 & 1.04 & 1.13 \\
\hline Fe II 49 & 5325.56 & 0.15 & 0.11 & 0.10 & 0.11 \\
\hline Ti II 69 & 5336.81 & 0.06 & 0.05 & 0.04 & 0.03 \\
\hline Fe II 48 & 5337.71 & 0.28 & 0.27 & 0.19 & 0.16 \\
\hline Fe II 49 & 5346.56 & 0.41 & 0.27 & 0.38 & 0.16 \\
\hline Fe II 48 & 5362.86 & 0.86 & 0.65 & 0.47 & 0.72 \\
\hline Ti II 80 & 5367.95 & 0.26 & 0.20 & 0.14 & 0.22 \\
\hline Cr II] 29 & 5392.95 & 0.51 & 0.38 & 0.36 & 0.23 \\
\hline Fe II 48 & 5414.09 & 0.35 & 0.18 & 0.27 & 0.38 \\
\hline
\end{tabular}


M.-P. Véron-Cetty et al.: IRAS 07598+6508, Online Material p 6

Table A.1. continued.

\begin{tabular}{lccccc}
\hline \hline Line & $\lambda(\AA)$ & KPNO 4-m & 2.3-m Bok & Keck & KPNO 2.1-m \\
\hline Fe II 49 & 5425.27 & 0.82 & 0.68 & 0.55 & 0.55 \\
Fe II] 55 & 5432.97 & 0.16 & 0.14 & 0.11 & 0.11 \\
Ti II] 68 & 5446.46 & 0.22 & 0.04 & 0.15 & 0.06 \\
Fe II 49 & 5477.67 & 0.17 & 0.13 & 0.13 & 0.07 \\
Cr II 50 & 5478.35 & 0.08 & 0.06 & 0.06 & 0.03 \\
Cr II 50 & 5502.05 & 0.14 & 0.11 & 0.12 & 0.08 \\
Cr II 50 & 5503.18 & 0.14 & 0.11 & 0.12 & 0.08 \\
Cr II 50 & 5508.60 & 0.14 & 0.11 & 0.12 & 0.08 \\
Fe II] 56 & 5525.14 & 0.23 & 0.18 & 0.19 & 0.33 \\
Ti II] 68 & 5529.94 & 0.11 & 0.09 & 0.09 & 0.17 \\
Fe II] 55 & 5534.86 & 0.67 & 0.57 & 0.49 & 0.25 \\
Fe II] 24 & 5864.54 & 0.08 & $\mathrm{n}$ & 0.20 & $\mathrm{n}$ \\
Na I D & 5889.89 & 0.43 & 0.75 & 0.32 & 0.54 \\
Na I D & 5895.92 & 0.57 & 0.25 & 0.56 & 0.21 \\
Fe II] 47 & 5932.05 & 0.07 & 0.02 & 0.09 & 0.08 \\
Fe II 182 & 5952.55 & 0.08 & $\mathrm{~h}$ & 0.07 & 0.05 \\
Fe II] 46 & 5991.39 & 0.22 & $\mathrm{~h}$ & 0.33 & 0.22 \\
Fe II] 46 & 6084.11 & 0.17 & 0.07 & 0.08 & 0.22 \\
Fe II] 46 & 6113.33 & 0.10 & 0.10 & 0.06 & 0.14 \\
Fe II] 46 & 6116.05 & 0.07 & 0.07 & 0.04 & 0.10 \\
Fe II] 46 & 6129.71 & 0.05 & 0.05 & 0.03 & 0.07 \\
Fe II 74 & 6147.74 & 0.41 & 0.32 & 0.28 & 0.37 \\
Fe II 74 & 6149.25 & 0.41 & 0.32 & 0.28 & 0.37 \\
Fe II] 46 & 6196.71 & 0.21 & 0.19 & 0.21 & 0.22 \\
Fe II 74 & 6238.37 & 0.25 & 0.43 & 0.22 & 0.07 \\
Fe II] 34 & 6239.37 & 0.07 & 0.13 & 0.07 & 0.02 \\
Fe II 74 & 6239.95 & 0.10 & 0.17 & 0.09 & 0.03 \\
Fe II 74 & 6247.55 & 0.78 & 0.22 & 0.76 & 1.27 \\
Fe II] 34 & 6279.83 & 0.16 & 0.10 & 0.23 & 0.18 \\
Fe II] 34 & 6307.53 & 0.16 & 0.10 & 0.23 & 0.18 \\
? & 6338.80 & 0.34 & 0.21 & 0.36 & 0.24 \\
Fe II 40 & 6369.45 & 0.58 & 0.51 & 0.55 & 0.66 \\
Fe II 74 & 6407.30 & 0.23 & 0.17 & 0.17 & 0.17 \\
Fe II 74 & 6416.89 & 0.47 & 0.34 & 0.34 & 0.35 \\
Fe II 40 & 6432.68 & 0.31 & 0.27 & 0.15 & 0.38 \\
Fe II 74 & 6456.39 & 0.91 & 0.68 & 0.47 & 0.58 \\
Fe II 40 & 6516.05 & 0.76 & 0.85 & 0.54 & 0.83 \\
\hline & & & & & \\
\hline
\end{tabular}

